\title{
Rnf149-related is an FGF/MAPK-independent regulator of pharyngeal muscle fate specification
}

\author{
Burcu Vitrinel ${ }^{1,2}$, Christine Voge ${ }^{\star 1}$, and Lionel Christiaen ${ }^{\star 2,3,4, \$}$
}

${ }^{1}$ Center for Genomics and Systems Biology, Department of Biology, New York University, New York, NY, USA

${ }^{2}$ Center for Developmental Genetics, Department of Biology, New York University, New York, NY, USA

${ }^{3}$ Sars International Centre for Marine Molecular Biology, University of Bergen, Bergen, Norway

${ }^{4}$ Department of Heart Disease, Haukeland University Hospital, Bergen, Norway

*equally contributing authors

\$corresponding author: Ic121@nyu.edu, lionel.christiaen@uib.no 


\section{Abstract}

During embryonic development, cell fate specification gives rise to dedicated lineages that underlie tissue formation. In olfactores, which comprise tunicates and vertebrates, the cardiopharyngeal field is formed by multipotent progenitors to both cardiac and branchiomeric muscles. The ascidian Ciona is a powerful model to study the cardiopharyngeal fate specification with cellular resolution, as only 2 pairs of cardiopharyngeal multipotent progenitors give rise to the heart and to pharyngeal muscles ( $a k a$ atrial siphon muscles, ASM). These progenitors are multilineage primed, in as much as they express a combination of early ASM- and heart-specific transcripts that become restricted to their corresponding precursors, following oriented asymmetric divisions. Here, we identify the primed gene Rnf149-related (Rnf149-r), which becomes restricted to the heart progenitors, but appears to regulate pharyngeal muscle fate specification in the cardiopharyngeal lineage. CRISPR/Cas9-mediated loss knock-out of Rnf149-r function impairs atrial siphon muscle morphogenesis, and down-regulates Tbx1/1O and Ebf, two key determinants of the pharyngeal muscle fate, while upregulating heart-specific gene expression. These phenotypes are reminiscent of loss of FGF-MAPK signaling in the cardiopharyngeal lineage, and integrated analysis of lineage-specific bulk RNA-seq profiling of loss-of-function perturbations identified a significant overlap between FGF-MAPK and Rnf149-r targets. However, functional interaction assays suggested the Rnf149-r does not directly modulate the activity of the FGF-MAPK-Ets1/2 pathway. Instead, we propose that $R n f 149-r$ acts both in parallel to the FGF-MAPK signaling on shared targets, as well as on FGF-MAPK-independent targets through (a) separate pathway(s). 


\section{Introduction}

During vertebrate development, the heart arises from distinct first and second heart fields (Buckingham, 2016; Kelly, 2020; Kelly et al., 2014). Clonal analyses have shown that first and second heart field progenitor cells arise from independent pools of multipotent Mesp1+ progenitors (Devine et al., 2014; Lescroart et al., 2014). However, common pools of progenitors give rise to the second heart field and the branchiomeric/pharyngeal muscles (Lescroart et al., 2010; Lescroart et al., 2015), referred to as cardiopharyngeal lineages.

Here, we leverage the simplicity of the cardiogenic lineage of Ciona, a simple tunicate and the closest living relatives to vertebrates among chordates (Delsuc et al., 2006; Putnam et al., 2008), to study cardiopharyngeal cell fate choices. Ciona allows us to study conserved early stages of cardiopharyngeal development with exceptional spatial and temporal resolution, and therefore emerged as a suitable model organism to understand developmental fate choices between cardiac and pharyngeal muscle cells (Kaplan et al., 2015). In Ciona, early lineage commitment typically restricts the competence of progenitors prior to lineage amplification by proliferation; by contrast, multipotent progenitors are amplified prior to fate specification in mammalian embryos (Evans Anderson and Christiaen, 2016). Like their vertebrate counterparts, Ciona's cardiopharyngeal lineage stems from multipotent progenitors, the trunk ventral cells (TVCs), which emerge from Mesp+ mesodermal progenitors. The TVCs are induced by Fibroblast growth factor/Mitogen-activated protein kinase (FGF/MAPK) signaling and migrate as bilateral pairs of cells, until the left and right pairs meet at the ventral midline and resume cell divisions (Figure 1a) (Christiaen et al., 2008; Davidson et al., 2005; Satou et al., 2004; Stolfi et al., 2010). Late TVCs undergo oriented asymmetric divisions that produce first heart precursors (FHPs) and secondary TVCs (STVCs), which then give rise to second heart precursors (SHPs) and pharyngeal muscle precursors (aka atrial muscle founder cells, ASMFs) (Figure 1a). STVCs activate $T b x 1 / 1 O$, the homolog of human $T B X 1$ that is required for cell-specific expression of the pharyngeal muscle determinant Ebf expression (Razy-Krajka et al., 2014; Stolfi et al., 2010; Wang et al., 2013). The FGF/MAPK signaling pathway is a key regulator of successive cardiopharyngeal fate decisions in Ciona. FGF/MAPK signaling is required for the induction of first and second-generation multipotent cardiopharyngeal progenitors (aka TVCs, and STVCs), and for the subsequent activation of the siphon/pharyngeal muscle program in their corresponding progenitors (Davidson et al., 2006; Razy-Krajka et al., 2018).

Over the past decade, we have extensively documented gene expression dynamics, and begun to decipher the underlying gene regulatory networks that govern early cardiopharyngeal development in Ciona. A key feature of the transcriptome dynamics that determine cardiopharyngeal transitions is 
multilineage priming, whereby multipotent cardiopharyngeal progenitors co-express early key regulators of the cardiac- and pharyngeal muscle-specific programs (Razy-Krajka et al., 2014; Wang et al., 2019). We surmise that multilineage transcriptional priming, while contributing to multipotency, also poses a challenge for subsequent fate specification following cell divisions, as fate-restricted progenitors inherit gene products that belong to the alternative fates, and might interfere commitment to a cardiac or pharyngeal muscle identity. For instance, single cell RNA-seq datasets indicated that first and second heart precursors inherit pharyngeal muscle-specific mRNAs that were down-regulated with varying dynamics after cell division, and upon commitment to a cardiac identity (Wang et al., 2019). We thus hypothesize that cell-type specific post-transcriptional regulatory mechanisms contribute to early cardiopharyngeal development, by remodeling inherited transcriptomes and proteomes upon fate specification and commitment.

Here, we focused on candidate transcriptional regulators showing differential gene expression in the cardiopharyngeal lineage, and identified Rnf149-related (hereafter referred to as Rnf149-r), a previously uncharacterized gene, as a necessary determinant of pharyngeal muscle identity. Rnf149-r is a transcriptionally primed heart marker in the cardiopharyngeal lineage (Wang et al., 2019) also encodes the postplasmic RNA (aka posterior end mark, PEM) Pen-1 (Yamada et al., 2005). Finally, Rnf149-r/Pen-1 is also dynamically expressed in various tissues during embryogenesis, including the central nervous system, the notochord and the epidermis, further suggesting pleiotropic functions. Rnf149-r's predicted protein structure revealed an atypical RNF organization, with a protease-associated domain but lacking the catalytic RING domain. In the cardiopharyngeal lineage, CRISPR/Cas9-mediated loss of Rnf149-r function disrupted pharyngeal muscle specification, most likely through inhibition of Ebf gene expression. The effects of $R n f 149-r^{C R I S P R}$ partially phenocopied loss of FGF/MAPK signaling, including a significant overlap of dysregulated genes from bulk RNA-seq experiments on FACS-purified cells. Finally, functional interaction assays indicated that Rnf149-r acts in parallel to the FGFR-MEK-Ets1/2 pathway upstream of $E b f$ activation, thus revealing the existence of FGF/MAPK-independent regulatory inputs into pharyngeal muscle specification. 


\section{Results}

\section{CRISPR/Cas9-mediated mutagenesis identifies the pharyngeal muscle determinant Rnf149-r}

We previously observed extensive multilineage transcriptional priming in multipotent cardiopharyngeal progenitors (Wang et al., 2019). This led us to hypothesize that lineage-specific post-transcriptional regulatory mechanisms contribute to remodelling transcriptomes and proteomes during heart vs. pharyngeal muscle fate decisions. To identify candidate post-transcriptional regulators, we catalogued genes encoding proteins annotated as RNA-binding and/or involved in ubiquitination pathways (GO terms GO:0003723 and GO:0016567, respectively), using the ANISEED database of GOSlim annotations curated using data from InterPro and UniProt (Supp. table 1) (Blum et al., 2021; Brozovic et al., 2016; UniProt Consortium, 2019). We integrated this table, containing 945 candidate genes, with previous cardiopharyngeal lineage-specific single cell RNA-seq (scRNA-seq) data, to identify candidate heart- and pharyngeal muscle-specific post-transcriptional regulators (Wang et al., 2019) (Supp. tables 1, 2). In a pilot approach, we selected 14 cardiopharyngeal genes that encode either ubiquitin ligase-related proteins (Rnf149-r, Asb2, Bag3/4, Rbms1/2/3) or RNA-binding proteins (Nova, Rbfox1/2/3, Rbms1/2/3, Rbm24/38, Qki, Ube2ql1, Pcbp3, Ube2j1, Otud3, Psmd14). We performed dual fluorescent in situ hybridization and immunohistochemistry (FISH-IHC) to verify their predicted expression in the heart and/or pharyngeal muscle precursors (Figure S1). We conducted lineage-specific loss-of-function analyses using the CRISPR/Cas9 system to target 6 of 15 candidate regulators (Gandhi et al., 2017; Gandhi et al., 2018; Haeussler et al., 2016; Stolfi et al., 2014). We collected swimming larvae (Stage 29/30; 26 hours post-fertilization), and scored the morphology of the cardiopharyngeal lineage, notably the presence or absence of the conspicuous pharyngeal/atrial siphon muscle (ASM) rings (Fig. 1b,c; (Stolfi et al., 2010)). We targeted the neurogenic bHLH factor-coding gene Neurogenin (Neurog ${ }^{\mathrm{CRISR}}$ ) as a control, since it is neither expressed in the cardiopharyngeal mesoderm nor thought to be involved in cardiopharyngeal development (Gandhi et al., 2017).

Lineage-specific CRISPR/Cas9-mediated mutagenesis of Rnf149-r showed the most penetrant phenotype, characterized by disrupted pharyngeal muscle morphogenesis (Chi-square test, p-value < 0.0001; Fig. 1d). Rnf149-r mutagenesis caused pharyngeal muscle morphogenesis defects, whereby the cells failed to migrate toward the atrial siphon placode (ASP) and form the ASM rings or crescents observed in control larvae (Stolfi et al., 2010). ASM rings were present in control conditions targeting either Neurog or Tyrosinase (Tyr), which is also inactive in the cardiopharyngeal lineage (Fig. 1b-e). To confirm the specificity of the $R n f 149-r^{C R I S P R}$ phenotype, we targeted $R n f 149-r$ using 2 sgRNAs targeting different positions of the coding sequence (Figure S2a). These sgRNAs produced similar 
pharyngeal muscle morphogenesis defects, whether used in combination or separately, indicating that both reagents contribute to the phenotype and are specific to Rnf149-r (Figure S2b). To further ascertain specificity, we expressed the CRISPR/Cas9 reagents alongside a rescue construct, consisting of a CRISPR/Cas9-resistant form of an Rnf149-r cDNA, with mutations in the protospacer adjacent motifs (PAMs) of both sgRNAs used (Rnf149- $\left.r^{m u t}\right)$, and expressed under the cardiopharyngeal progenitor-specific Foxf enhancer (Beh et al., 2007). Remarkably, the proportion of larvae showing signs of normal ASM morphogenesis increased from 20\% in Rnf149-r ${ }^{\text {CRISPR }}$ animals to $70 \%$ following co-expression of $R n f 149-r^{\text {mut }}$ (Fig. 1e). This experiment demonstrated that the observed pharyngeal muscle phenotype is specifically caused by the loss of Rnf149-r function in the cardiopharyngeal lineage.

Consistent with a potential role in cardiopharyngeal development, the uncharacterized gene Ring finger protein 149 related ( $R n f 149-r)$ is transcriptionally primed in multipotent progenitors of tailbud embryos (stage 22), and restricted to the heart progenitors in swimming larvae (Figure S3) (Wang et al., 2019). To understand whether the phenotype is primarily caused by late migration, or early fate specification defects, we assayed expression of the essential ASM determinant and specific marker Ebf, in hatching larvae (stage 26; (Racioppi et al., 2019; Razy-Krajka et al., 2014; Stolfi et al., 2010)). The ASM-specific factor $E b f$ is necessary and sufficient to suppress the heart program, and impose the pharyngeal muscle fate in the cardiopharyngeal lineage (Razy-Krajka et al., 2014; Stolfi et al., 2010). Rnf149-r mutagenesis caused lineage-specific loss of Ebf expression, which typically produced ectopic cardiac specification and ASM fate specification defects, thus abolishing migration toward the ASP (Figure 2a, b) (Razy-Krajka et al., 2014; Stolfi et al., 2014).

As we observed phenotypic defects at 18 and $26 \mathrm{hpf}$, we asked whether earlier cardiopharyngeal development is affected by loss of Rnf149-r function. We tested TVC migration and expression of the TVC marker Hand-r expression at the late tailbud stage $\left(12 \mathrm{hpf}\right.$ at $\left.18^{\circ} \mathrm{C}\right)$. However, we did not observe any difference between the experimental and control animals (Figure S4). In light of these results, we propose that $R n f 149-r$ function is necessary for the transition to the pharyngeal muscle fate from a multipotent cardiopharyngeal progenitor state.

\section{Rnf149-r encodes an atypical ubiquitin ligase-related protein}

We identified $R n f 149-r$ for CRISPR/Cas9 mutagenesis as a candidate post-transcriptional regulator, because it was annotated as a RING-finger domain containing protein, which typically comprise E3-ubiquitin ligases. However, upon closer inspection, we found that the predicted Ciona Rnf149-r 
protein lacks a RING domain, but contains a Protease-Associated (PA) domain (Figure S5). PA domains in humans and other higher vertebrates can co-exist with RING domains, as well as other functionally active domains, such as EGF, RZF family and transferrin receptor (Mahon and Bateman, 2000).

Like other organisms, the Ciona genome encodes a variety of PA-domain-containing proteins. This domain in Ciona occurs as the only defined domain in 2 predicted proteins, including Rnf149-r. The other PA-domain proteins also contain associated glycosidase domains, Zn-independent exopeptidase domains, transferrin receptor-like dimerization domains and/or RING domains (Figure S5, Supp. table 3). Our sequence analyses showed that Rnf149-r has one homolog with similar domain architecture in Ciona, Rnf150, prompting us to hypothesize that Rnf149-r may act as a natural dominant-negative inhibitor of Rnf15o function. However, CRISPR/Cas9-mediated loss of Rnf150 function did not cause any overt phenotype, nor did it rescue loss of Rnf149-r function, leading us to rule out Rnf150 as mediator of the Rnf149-r ${ }^{\mathrm{CRISPR}}$ phenotype (Figure S6).

\section{Rnf149-r regulates cardiopharyngeal fates independently of FGF/MAPK signaling}

Fibroblast growth factor/Mitogen-activated protein kinase (FGF/MAPK) signaling is a key regulator of cardiopharyngeal fates in Ciona, with established roles in early Mesp+ mesoderm specification, and multipotent progenitor induction and migration (Christiaen et al., 2008; Davidson et al., 2006). Sustained FGF-MAPK activity leads to localized Ebf expression in ASM precursors, while its exclusion from first and second heart precursors permits cardiac specification (Razy-Krajka et al., 2018; Wang et al., 2019). MAPK activity in early pharyngeal muscle progenitors initiates Ebf expression, until Ebf accumulation permits MAPK-independent auto-activation. This switch is surmised to explain the transition from the multipotent state to committed pharyngeal muscle fate (Razy-Krajka et al., 2018).

The $R n f 149-r^{C R I S P R}$ phenotype resembles loss of MAPK function, as observed following lineage-specific misexpression of a dominant-negative form of the FGF receptor, or by treatment with the MEK inhibitor Uo126 (Razy-Krajka et al., 2018). Moreover, in vitro studies showed that human RNF149 interacts with and induces ubiquitination of the classic regulator of Mek1/2 and MAPK signaling, Braf (Hong et al., 2012). We thus hypothesized that Rnf149-r regulates the pharyngeal muscle fate choice by interacting with FGF/MAPK signaling .

To test these hypotheses, we overexpressed constitutively active forms of M-Ras and Mek1/2 in parallel with $R n f 149-r^{\text {CRISPR }}$, and used $E b f$ expression as the readout of pharyngeal muscle fate specification. Overexpression of constitutively active forms of either M-Ras or Mek1/2 suffices to cause ectopic Ebf expression in the cardiopharyngeal lineage, and abolish the heart fate (Razy-Krajka et al., 2018) (Figure 3). We first combined $R n f 149-r^{\mathrm{CRISPR}}$ with overexpression of a defined constitutively 
active form of M-Ras, M-Ras ${ }^{\mathrm{G} 22 \mathrm{~V}}$ (called M-Ras ${ }^{\mathrm{CA}}$ here on), which is the only Ras homolog in Ciona and acts in the FGF/MAPK pathway (Keduka et al., 2009). We also overexpressed a constitutively active form of Mek1/2, Mek1/2 ${ }^{\mathrm{S} 220 \mathrm{E}, \mathrm{S} 216 \mathrm{D}}$ (Mek ${ }^{\mathrm{CA}}$ here on) (Razy-Krajka et al., 2018), a key regulator of MAPK activity downstream of M-Ras (Figure 3a). We expressed these constructs using the TVC-specific Foxf enhancer to restrict the misexpression of the constitutively active mutants to the TVCs and their progeny. Accordingly, we did not observe any unrelated, early cardiopharyngeal development defects. In either case, the effects of $R n f 149^{-} r^{\text {CRISPR }}$ dominated ectopic activation of the Ras-Mek pathway and blocked Ebf expression (Figure 3). The dominance of the Rnf149 ${ }^{\mathrm{CRISPR}}$ phenotype was even more clearly observable when using Foxf $>L a c Z$ to label transfected cells and account for mosaicism (Figure S7). These results indicate that Rnf149-r function is required either in parallel to the FGF/MAPK pathway, or downstream of Mek, for proper Ebf expression, and by extension for pharyngeal muscle specification.

The transcription factor Ets1/2 is a known downstream effector of the FGF/MAPK pathway, presumed to control cardiopharyngeal development in Ciona (Davidson et al., 2006; Miya and Nishida, 2003). We tested possible functional interactions between $R n f 149-r$ and Ets1/2, and found that $R n f 149-r^{\mathrm{CRISPR}}$ inhibits the ectopic Ebf expression phenotype obtained with Ets1/2 overexpression, as well (Figure 3).

This systematic dominance of the Rnf149- $r^{C R I S P R}$ phenotype over gain of either M-Ras, Mek1/2 or Ets1/2 function suggested that the uncharacterized protein Rnf149-r acts in parallel to the FGF/MAPK pathway upstream of $E b f$ activation during pharyngeal muscle specification. This is consistent with the above conclusion Rnf149-r functions later than late tailbud stage, since FGF/MAPK is already active and necessary for multipotent progenitor induction and maintenance (Davidson et al. 2006; $\underline{\text { Razy-Krajka et al. 2018). }}$

\section{Rnf149-r regulates both MAPK-dependent and independent genes}

To explore the broader transcriptional impact of Rnf149-r loss-of-function, we performed lineage-specific bulk RNA-seq experiment by FACS-purifying cardiopharyngeal cells following CRISPR/Cas9-mediated mutagenesis of either Rnf149-r, or Tyrosinase as a control, in biological triplicates. Out of 15,232 genes quantified, 190 were significantly differentially expressed, with a false discovery rate (FDR) smaller than 0.05. Out of 190, 166 of these genes were upregulated and 24 were downregulated in the $R n f 149-r^{C R I S P R}$ condition, compared to Tyr $r^{C R I S P R}$ controls. Rnf149-r as well as three known pharyngeal muscle progenitor cell-specific markers, namely Ebf, Htr7 and Tbx1/1O were all significantly downregulated in the Rnf149- ${ }^{\text {CRISPR }}$ condition (Razy-Krajka et al., 2018; Wang et al., 2019) 
(Figure 4a, Supp. table 5). By contrast, the classic cardiac determinants Nk4/Nkx2-5, Gata4/5/6 and Hand, and the heart precursor markers Slit, Lrp4/8 and Mmp21, were slightly upregulated, but not significantly (Supp. table 5).

As MAPK is a key regulator of fate in the cardiopharyngeal lineage, we compared the significantly changing expression levels with the overexpression of the dominant negative Fgf receptor, $F o x f>F g f r{ }^{D N}$. We observed a positive correlation between the fold-changes for both experiments when only the significantly changing genes in the $R n f 149-r^{\mathrm{CRISPR}}$ experiment were considered (Figure $4 \mathrm{~b}$ ). The upregulated genes in the RNA-seq were significantly enriched in FGF-MAPK inhibited genes and the downregulated genes are significantly enriched in FGF-MAPK-dependent genes. A Fisher's test done between the $F g f r^{\mathrm{DN}}$ and $R n f 14$ - $^{C R I S P R}$ RNA-seq show that there is significant overlap between the genes that are significantly changing in comparison to their internal controls $(\mathrm{p}$-value $=4.7 \mathrm{E}-\mathrm{o} 8$, odds ratio $=$ 3.3) (Figure 4c). These observations are consistent with a partial conversion of pharyngeal muscle progenitors to a heart-like fate in $R n f 149-r^{\mathrm{CRISPR}}$.

\section{Discussion}

In this study, we identified Rnf149-r as a new regulator of cardiopharyngeal lineage development in the tunicate Ciona. We showed that the predicted Rnf149-r sequence contains a protein-protein interaction domain, and CRISPR/Cas9-mediated loss-of-function affects pharyngeal muscle fate specification. We developed molecular tools to study the function of this gene using CRISPR/Cas9 reagents and epistasis assays via overexpression and expression of dominant-negative reagents altering the activity of the FGF/MAPK pathway. Our analyses suggested that Rnf149-r acts in parallel to the FGF/MAPK pathway on shared targets. We thus uncovered a potential entry point for a novel pathway regulating cardiac vs. pharyngeal muscle fate specification.

Recent studies from our lab have shown that transcriptional inputs from FGF/MAPK signaling are required at successive stages for pharyngeal muscle specification in Ciona (Razy-Krajka et al., 2018; Wang et al., 2019). CRISPR/Cas9-mediated loss of Rnf149-r function phenocopied the loss of Ebf expression and pharyngeal muscle specification induced by inhibition of FGF-MAPK signaling, and an RNF149 homolog was shown to regulate Raf, we thus hypothesized that Rnf149-r regulates MAPK signaling. However, Rnf149-r loss of function did not alter expression of the multipotent progenitor marker Hand-r, the maintenance of which relies on continuous inputs from MEK activity. In addition, while lineage-specific bulk RNA-seq analysis of either Rnf149-r ${ }^{\mathrm{CRISPR}}$ or Fgfr inhibition correlated and 
showed significant overlap of differentially expressed genes, including known STVC and ASMF markers such as $H \operatorname{tr} 7, T b x 1 / 1 O$ and $E b f$, there were substantial fractions of genes dysregulated by perturbation of either FGF-MAPK or Rnf149-r alone. Moreover, functional interaction assays between Rnf149-r ${ }^{\text {CRISPR }}$ and gain of Ras, Mek and Ets1/2 functions, indicated that Rnf149-r activity was required for each gain-of-function perturbation to cause ectopic Ebf expression, suggesting that $R n f 149-r$ acts in parallel to FGF-MAPK-Ets, targeting a partially shared set of genes.

We note several possible future extensions of this work. First, as Rnf149-r is a primed heart gene, it might itself be subject to post-transcriptional regulation. Second, the role of the protein interaction domain in Rnf149-r is not known, and future pulldown experiments followed by Mass spectrometry-based identification of interaction partners would provide insights into Rnf149-r molecular function and the hypothesized regulatory pathway involved. 


\section{Methods}

\section{Ciona robusta handling}

Wild Ciona robusta adults were obtained from M-REP (Carlsbad, CA, USA), and kept under constant light to avoid spawning. Gametes from several animals were collected separately for in vitro cross-fertilization followed by dechorionation and electroporation as previously described (Christiaen et al., 2009b). The embryos were cultured in filtered artificial seawater (FASW) in agarose-coated plastic Petri dishes at $18^{\circ} \mathrm{C}$. We electroporated $50 \mu \mathrm{g}$ of constructs for FACS purification (Mesp $>$ tagRFP, MyoD905>eGFP and Hand-r>tagBFP) and $70 \mu \mathrm{g}$ of experimental constructs (Mesp $>$ LacZ, Mesp $>$ Fgfr ${ }^{D N}$, Mesp $\left.>M k^{S 216 D, S 22 O E}\right)$.

\section{CRISPR/Cas9-mediated mutagenesis}

Six to eight single guide RNAs (sgRNA) per gene with Doench scores (http://crispor.tefor.net, v4.0) (Haeussler et al., 2016) higher than 60 were designed to induce mutagenesis using CRISPR/Cas9 in the B7.5 lineage as described (Gandhi et al., 2017) (Supplementary table 4). The efficiency of sgRNAs was evaluated using the peakshift method as described (Gandhi et al., 2017). CRISPR/Cas9-mediated deletions were also evaluated by PCR-amplification directly from embryo lysates following electroporated with Ef1a>nls::Cas9-Gem::nls. sgRNAs were expressed using the Ciona robusta U6 promoter (Stolfi et al., 2014). For each gene, two or three guide RNAs were used to total $50 \mu \mathrm{g}$, in combination with $25 \mu \mathrm{g}$ of each expression plasmid. $25 \mu \mathrm{g}$ of Mesp>nls::Cas9-Gem::nls plasmid was co-electroporated with guide RNA expression plasmids for B7.5 lineage-specific CRISPR/Cas9-mediated mutagenesis. One guide RNA was used to mutagenize Tyrosinase and Neurogenin, which are not expressed in the cardiopharyngeal lineage and thus used to control the specificity of the CRISPR/Cas9 system (Wang et al., 2019).

\section{Molecular cloning of Rnf149- $\boldsymbol{r}^{\text {mut }}$ rescue construct}

Coding sequence for wild-type Rnf149-r (KH.C2.994) was obtained from the plasmid contained in the C. intestinalis full ORF Gateway-compatible clone VES66_B12. Insertion of the product into the expressing vector was performed using In-fusion (Clontech, Mountain View, CA) protocol. Oligonucleotide directed mutagenesis and two-step overlap PCRs were used to generate the point mutated form $R n f 149-r^{\text {mut }}$ from the corresponding wild-type sequences. We used oligonucleotide directed mutagenesis to generate mismatches in the PAM sequences adjacent to the sgRNA targets. Because of the disturbance of a correct PAM sequence (NGG, (reverse complement CCN)), overexpressed $R n f 149-r^{\text {mut }}$ is resistant to the Cas9 nuclease activity.

\section{Fluorescent in situ hybridization immunohistochemistry (FISH-IHC) of Ciona embryos}

The following ISH probes were obtained from plasmids contained in the $C$. intestinalis full ORF Gateway-compatible clone: Rnf149-r (VES66_B12), Bag3/4 (VES90_Eo4), Rbm24/38 (VES87_P24), Asb2 (VES74_P16), Qki (VES69_Ao6), Rbms1/2/3 (VES9o_E05), Psmd14 (VES70_A18), Ube2ql1 
(VES68_H10), Otud3 (VES70_G23), Natn1 (VES91_K15) and: C. intestinalis gene collection release I: Smurf1/2 (GC20g07), Pcbp3 (GCo7eo8), Ube2j1 (GCo3lo8).

PCR amplification of transcription templates was with the following oligos: M13 fw (5'-GTAAAACGACGGCCAGT- $\left.3^{\prime}\right)$ and M13 rev (5'-CAGGAAACAGCTATGAC- $\left.3^{\prime}\right)$. DIG- and FLUORESCEIN-labeled probes were transcribed with $\mathrm{T}_{7}$ RNA polymerase (Roche) using DIG labeling (Roche) and purified with the RNeasy Mini Kit (Qiagen). Antisense RNA probes were synthesized as described (Racioppi et al., 2014). In vitro antisense RNA synthesis was performed using T7 RNA Polymerase (Roche, Cat. No. 10881767001) and DIG RNA Labeling Mix (Roche, Cat. No. 11277073910).

Embryos were harvested and fixed at desired developmental stages for $2 \mathrm{~h}$ in 4\% MEM-PFA (4\% paraformaldehyde, o.1 M MOPS pH 7.4, 0.5 M NaCl, 1 mM EGTA, 2 mM MgSO4, 0.05\% Tween 20), rinsed in cold phosphate-buffered saline (PBS), gradually dehydrated for $1.5 \mathrm{~h}$ and stored in $75 \%$ ethanol at $-20^{\circ} \mathrm{C}$. They were then rehydrated gradually using a methanol/PBS-Tween series, and whole mount fluorescent in situ hybridization was performed as previously described (Razy-Krajka et al., 2014; Wang et al., 2013). Anti-Digoxigenin-POD Fab fragment (Roche, IN) was first used to detect the hybridized probes, then the signal was revealed using Tyramide Signal Amplification (TSA) with Fluorescein TSA Plus Evaluation Kit (Perkin Elmer, MA).

For immunohistochemistry, samples were blocked in Tris-NaCl-Blocking buffer (Blocking Reagent, PerkinElmer) for $2-4 \mathrm{~h}$ preceding primary antibody incubation and $1 \mathrm{~h}$ preceding secondary antibody incubation. Antibody solutions were prepared in Tris-NaCl-Blocking buffer and incubated for $1-2 \mathrm{~h}$ at room temperature, followed by an overnight incubation at $4{ }^{\circ} \mathrm{C}$. Anti- $\beta$-galactosidase monoclonal mouse antibody (Promega, 1:500) was co-incubated with anti-mCherry polyclonal rabbit antibody (Bio Vision, Cat. No. 5993-100, 1:500) for immunodetection of Mesp >nls::lacZ and Mesp >hCD4::mCherry products respectively. Goat anti-mouse secondary antibodies coupled with AlexaFluor-555 and AlexaFluor-633 were used to detect $\beta$-galactosidase-bound mouse antibodies and mCherry-bound rabbit antibodies after the TSA reaction. Antibody washes were performed using Tris-NaCl-Tween buffer. Samples were mounted in ProLong Gold Antifade Mountant (ThermoFisher Scientific, Waltham, MA, Catalog number P36930) and stored in $4^{\circ} \mathrm{C}$.

Images were acquired with an inverted Leica TCS SP8 X confocal microscope, using an HC PL APO $\times 63 / 1.30$ objective. Maximum projections were processed with maximum projection tools from the Leica software LAS-AF.

\section{Cell dissociation and FACS-purification of Ciona robusta cells}

Sample dissociation and FACS were performed as previously described (Christiaen et al., 2009a; Wang et al., 2018). Embryos and larvae were harvested at $15 \mathrm{hpf}$ in $5 \mathrm{ml}$ borosilicate glass tubes (Fisher Scientific, Waltham, MA. Cat.No. 14-961-26) and washed with $2 \mathrm{ml}$ calcium- and magnesium-free artificial seawater (CMF-ASW: $449 \mathrm{mM} \mathrm{NaCl}, 33 \mathrm{mM} \mathrm{Na}_{2} \mathrm{SO}_{4}, 9 \mathrm{mM} \mathrm{KCl}, 2.15 \mathrm{mM} \mathrm{NaHCO}, 10 \mathrm{mM}$ Tris-Cl pH 8.2, 2.5 mM EGTA). Embryos and larvae were dissociated in $2 \mathrm{ml} \mathrm{0.2 \%} \mathrm{trypsin} \mathrm{(w/v,} \mathrm{Sigma,}$ T- 4799) in CMF-ASW by pipetting with glass Pasteur pipettes. The dissociation was stopped by adding $2 \mathrm{ml}$ filtered ice cold 0.05\% BSA CMF-ASW. Dissociated cells were passed through a $40 \mu \mathrm{m}$ cell-strainer and collected in $5 \mathrm{ml}$ polystyrene round-bottom tube (Corning Life Sciences, Oneonta, New York). Cells 
were collected by centrifugation at $800 \mathrm{~g}$ for $3 \mathrm{~min}$ at $4^{\circ} \mathrm{C}$, followed by two washes with ice cold CMF-ASW. Cell suspensions were filtered again through a $40 \mu \mathrm{m}$ cell-strainer and kept on ice.

Cardiopharyngeal lineage cells were labeled with Mesp $>$ tagRFP and Hand-r>tagBFP reporters. The mesenchyme cells were counter-selected using MyoD905>GFP. Dissociated cells were loaded in a BD FACS AriaTM cell sorter. $488 \mathrm{~nm}$ laser, FITC filter was used for GFP; $407 \mathrm{~nm}$ laser, $561 \mathrm{~nm}$ laser, DsRed filter was used for tagRFP and Pacific BlueTM filter was used for tagBFP.

\section{RNA-seq library preparation, sequencing and analysis}

To profile transcriptomes of FACS-purified cells from $R n f 149-r^{C R I S P R}$ and control samples, 1,00o cells were directly sorted in $100 \mu$ lysis buffer from the RNAqueous-Micro Total RNA Isolation Kit (Ambion). For each condition, samples were obtained in three biological replicates. The total RNA extraction was performed following the manufacturer's instruction. The quality and quantity of total RNA was checked using Agilent RNA ScreenTape (Agilent) using the 4200 TapeStation system. RNA samples with RNA Integrity Number (RIN) > 8 were kept for downstream cDNA synthesis. 250-2000 pg of total RNA was loaded as a template for cDNA synthesis using the SMART-Seq v4 Ultra Low Input RNA Kit (Clontech) with template switching technology. RNA-Seq Libraries were prepared and barcoded using Ovation Ultralow System V2 (NuGen). Six barcoded samples were pooled in one lane of the flow cell and sequenced by Illumina NextSeq 750 (MidOutput run). Paired-end 75 bp length reads were obtained from all the bulk RNA-seq libraries. Bulk RNA-seq libraries were aligned using STAR 2.7.0a (Zhang et al., 2018) with the parameters '--runThreadN 6 --outSAMtype BAM SortedByCoordinate \--outSAMunmapped Within \--outSAMattributes Standard '. Counts were obtained using featureCounts, a function of subread (Liao et al., 2014; Liao et al., 2019). Differential expression was calculated using DESeq2 (Love et al., 2014).

\section{Data availability}

The RNA-seq data were deposited in the Gene Expression Omnibus (GEO) under accession GSE171152. Previously published bulk RNA-seq data that was used here for comparison in Figure 4 can be found on GEO with accession GSE99846.

\section{Acknowledgements}

B.V. acknowledges funding by American Heart Association grant \#18PRE33990254, NYU Fleur Strand Graduate Fellowship and NYU GSAS Dean's Dissertation Fellowship. C.V. acknowledges funding by the National Institutes of Health 5R35GM127089. L.C. acknowledges funding by the Leducq Foundation, award 15CVDo1, and by the National Institute of Health, award Ro1 HL108643. We thank Yelena Bernadskaya for the critical reading of and feedback on the manuscript. We thank Alberto Stolfi and Shashank Gandhi for Nova ${ }^{\mathrm{CRISPR}}$ and Nova riboprobe and Manar Elzaky for Rnf149-r structure analysis. We thank NYU Genomics Core facility for technical support for FACS. 


\section{References}

Alvarez, M. J., Shen, Y., Giorgi, F. M., Lachmann, A., Ding, B. B., Ye, B. H. and Califano, A. (2016). Functional characterization of somatic mutations in cancer using network-based inference of protein activity. Nat. Genet. 48, 838-847.

Beh, J., Shi, W., Levine, M., Davidson, B. and Christiaen, L. (2007). FoxF is essential for FGF-induced migration of heart progenitor cells in the ascidian Ciona intestinalis. Development 134, 3297-3305.

Blum, M., Chang, H.-Y., Chuguransky, S., Grego, T., Kandasaamy, S., Mitchell, A., Nuka, G., Paysan-Lafosse, T., Qureshi, M., Raj, S., et al. (2021). The InterPro protein families and domains database: 20 years on. Nucleic Acids Res. 49, D344-D354.

Brozovic, M., Martin, C., Dantec, C., Dauga, D., Mendez, M., Simion, P., Percher, M., Laporte, B., Scornavacca, C., Di Gregorio, A., et al. (2016). ANISEED 2015: a digital framework for the comparative developmental biology of ascidians. Nucleic Acids Res. 44, D808-18.

Buckingham, M. (2016). First and Second Heart Field. Congenital Heart Diseases: The Broken Heart 25-40.

Christiaen, L., Davidson, B., Kawashima, T., Powell, W., Nolla, H., Vranizan, K. and Levine, M. (2008). The transcription/migration interface in heart precursors of Ciona intestinalis. Science 320, 1349-1352.

Christiaen, L., Wagner, E., Shi, W. and Levine, M. (2009a). Isolation of Individual Cells and Tissues from Electroporated Sea Squirt (Ciona) Embryos by Fluorescence-Activated Cell Sorting (FACS). Cold Spring Harbor Protocols 2009, db.prot5349-pdb.prot5349.

Christiaen, L., Wagner, E., Shi, W. and Levine, M. (2009b). Isolation of sea squirt (Ciona) gametes, fertilization, dechorionation, and development. Cold Spring Harb. Protoc. 2009, db.prot5344.

Christiaen, L., Stolfi, A. and Levine, M. (2010). BMP signaling coordinates gene expression and cell migration during precardiac mesoderm development. Dev. Biol. 340, 179-187.

Davidson, B., Shi, W. and Levine, M. (2005). Uncoupling heart cell specification and migration in the simple chordate Ciona intestinalis. Development 132, 4811-4818.

Davidson, B., Shi, W., Beh, J., Christiaen, L. and Levine, M. (2006). FGF signaling delineates the cardiac progenitor field in the simple chordate, Ciona intestinalis. Genes Dev. 20, 2728-2738.

Delsuc, F., Brinkmann, H., Chourrout, D. and Philippe, H. (2006). Tunicates and not cephalochordates are the closest living relatives of vertebrates. Nature 439, 965-968.

Devine, W. P., Patrick Devine, W., Wythe, J. D., George, M., Koshiba-Takeuchi, K. and Bruneau, B. G. (2014). Early patterning and specification of cardiac progenitors in gastrulating mesoderm. eLife $\mathbf{3}$,.

Evans Anderson, H. and Christiaen, L. (2016). Ciona as a Simple Chordate Model for Heart Development and Regeneration. Journal of Cardiovascular Development and Disease 3, 25. 
Gandhi, S., Haeussler, M., Razy-Krajka, F., Christiaen, L. and Stolfi, A. (2017). Evaluation and rational design of guide RNAs for efficient CRISPR/Cas9-mediated mutagenesis in Ciona. Dev. Biol. 425, 8-20.

Gandhi, S., Razy-Krajka, F., Christiaen, L. and Stolfi, A. (2018). CRISPR Knockouts in Ciona Embryos. Adv. Exp. Med. Biol. 1029, 141-152.

Haeussler, M., Schönig, K., Eckert, H., Eschstruth, A., Mianné, J., Renaud, J.-B., Schneider-Maunoury, S., Shkumatava, A., Teboul, L., Kent, J., et al. (2016). Evaluation of off-target and on-target scoring algorithms and integration into the guide RNA selection tool CRISPOR. Genome Biol. 17, 148.

Hong, S.-W., Jin, D.-H., Shin, J.-S., Moon, J.-H., Na, Y.-S., Jung, K.-A., Kim, S.-M., Kim, J. C., Kim, K.-P., Hong, Y. S., et al. (2012). Ring finger protein 149 is an E3 ubiquitin ligase active on wild-type v-Raf murine sarcoma viral oncogene homolog B1 (BRAF). J. Biol. Chem. 287, 24017-24025.

Hotta, K., Mitsuhara, K., Takahashi, H., Inaba, K., Oka, K., Gojobori, T. and Ikeo, K. (2007). A web-based interactive developmental table for the ascidian Ciona intestinalis, including 3D real-image embryo reconstructions: I. From fertilized egg to hatching larva. Dev. Dyn. 236, 1790-1805.

Hotta, K., Dauga, D. and Manni, L. (2020). The ontology of the anatomy and development of the solitary ascidian Ciona: the swimming larva and its metamorphosis. Sci. Rep. 10, 17916.

Kaplan, N., Razy-Krajka, F. and Christiaen, L. (2015). Regulation and evolution of cardiopharyngeal cell identity and behavior: insights from simple chordates. Curr. Opin. Genet. Dev. 32, 119-128.

Keduka, E., Kaiho, A., Hamada, M., Watanabe-Takano, H., Takano, K., Ogasawara, M., Satou, Y., Satoh, N. and Endo, T. (2009). M-Ras evolved independently of R-Ras and its neural function is conserved between mammalian and ascidian, which lacks classical Ras. Gene 429, 49-58.

Kelly, R. G. (2020). Advances in the Second Heart Field. Molecular Mechanism of Congenital Heart Disease and Pulmonary Hypertension 301-307.

Kelly, R. G., Buckingham, M. E. and Moorman, A. F. (2014). Heart fields and cardiac morphogenesis. Cold Spring Harb. Perspect. Med. 4,.

Lescroart, F., Kelly, R. G., Le Garrec, J.-F., Nicolas, J.-F., Meilhac, S. M. and Buckingham, M. (2010). Clonal analysis reveals common lineage relationships between head muscles and second heart field derivatives in the mouse embryo. Development 137, 3269-3279.

Lescroart, F., Chabab, S., Lin, X., Rulands, S., Paulissen, C., Rodolosse, A., Auer, H., Achouri, Y., Dubois, C., Bondue, A., et al. (2014). Early lineage restriction in temporally distinct populations of Mesp1 progenitors during mammalian heart development. Nat. Cell Biol. 16, 829-840.

Lescroart, F., Hamou, W., Francou, A., Théveniau-Ruissy, M., Kelly, R. G. and Buckingham, M. (2015). Clonal analysis reveals a common origin between nonsomite-derived neck muscles and heart myocardium. Proc. Natl. Acad. Sci. U. S. A. 112, 1446-1451. 
Liao, Y., Smyth, G. K. and Shi, W. (2014). featureCounts: an efficient general purpose program for assigning sequence reads to genomic features. Bioinformatics 30, 923-930.

Liao, Y., Smyth, G. K. and Shi, W. (2019). The R package Rsubread is easier, faster, cheaper and better for alignment and quantification of RNA sequencing reads. Nucleic Acids Research 47, e47-e47.

Love, M. I., Huber, W. and Anders, S. (2014). Moderated estimation of fold change and dispersion for RNA-seq data with DESeq2. Genome Biol. 15, 550.

Mahon, P. and Bateman, A. (2000). The PA domain: a protease-associated domain. Protein Sci. 9, 1930-1934.

Mittal, S., Subramanyam, D., Dey, D., Kumar, R. V. and Rangarajan, A. (2009). Cooperation of Notch and Ras/MAPK signaling pathways in human breast carcinogenesis. Mol. Cancer 8, 128.

Miya, T. and Nishida, H. (2003). An Ets transcription factor, HrEts, is target of FGF signaling and involved in induction of notochord, mesenchyme, and brain in ascidian embryos. Dev. Biol. 261, $25-38$.

Putnam, N. H., Butts, T., Ferrier, D. E. K., Furlong, R. F., Hellsten, U., Kawashima, T., Robinson-Rechavi, M., Shoguchi, E., Terry, A., Yu, J.-K., et al. (2008). The amphioxus genome and the evolution of the chordate karyotype. Nature 453, 1064-1071.

Racioppi, C., Kamal, A. K., Razy-Krajka, F., Gambardella, G., Zanetti, L., di Bernardo, D., Sanges, R., Christiaen, L. A. and Ristoratore, F. (2014). Fibroblast growth factor signalling controls nervous system patterning and pigment cell formation in Ciona intestinalis. Nat. Commun. 5, 4830.

Racioppi, C., Wiechecki, K. A. and Christiaen, L. (2019). Combinatorial chromatin dynamics foster accurate cardiopharyngeal fate choices. Elife $\mathbf{8}$.

Razy-Krajka, F., Lam, K., Wang, W., Stolfi, A., Joly, M., Bonneau, R. and Christiaen, L. (2014). Collier/OLF/EBF-dependent transcriptional dynamics control pharyngeal muscle specification from primed cardiopharyngeal progenitors. Dev. Cell 29, 263-276.

Razy-Krajka, F., Gravez, B., Kaplan, N., Racioppi, C., Wang, W. and Christiaen, L. (2018). An FGF-driven feed-forward circuit patterns the cardiopharyngeal mesoderm in space and time. Elife 7,.

Satou, Y., Imai, K. S. and Satoh, N. (2004). The ascidian Mesp gene specifies heart precursor cells. Development 131, 2533-2541.

Stolfi, A., Gainous, T. B., Young, J. J., Mori, A., Levine, M. and Christiaen, L. (2010). Early chordate origins of the vertebrate second heart field. Science 329, 565-568.

Stolfi, A., Gandhi, S., Salek, F. and Christiaen, L. (2014). Tissue-specific genome editing in Ciona embryos by CRISPR/Cas9. Development 141, 4115-4120.

Sundaram, M. V. (2005). The love-hate relationship between Ras and Notch. Genes Dev. 19, $1825^{-1839 .}$

Tremblay, I., Paré, E., Arsenault, D., Douziech, M. and Boucher, M.-J. (2013). The 
MEK/ERK pathway promotes NOTCH signalling in pancreatic cancer cells. PLoS One 8, e85502.

UniProt Consortium (2019). UniProt: a worldwide hub of protein knowledge. Nucleic Acids Res. 47, D506-D515.

Wang, W., Razy-Krajka, F., Siu, E., Ketcham, A. and Christiaen, L. (2013). NK4 antagonizes Tbx1/10 to promote cardiac versus pharyngeal muscle fate in the ascidian second heart field. PLoS Biol. 11, e1001725.

Wang, W., Racioppi, C., Gravez, B. and Christiaen, L. (2018). Purification of Fluorescent Labeled Cells from Dissociated Ciona Embryos. Adv. Exp. Med. Biol. 1029, 101-107.

Wang, W., Niu, X., Stuart, T., Jullian, E., Mauck, W. M., 3rd, Kelly, R. G., Satija, R. and Christiaen, L. (2019). A single-cell transcriptional roadmap for cardiopharyngeal fate diversification. Nat. Cell Biol. 21, 674-686.

Yamada, L., Kobayashi, K., Satou, Y. and Satoh, N. (2005). Microarray analysis of localization of maternal transcripts in eggs and early embryos of the ascidian, Ciona intestinalis. Dev. Biol. 284, 536-550.

Zhang, P., Hung, L.-H., Lloyd, W. and Yeung, K. Y. (2018). Hot-starting software containers for STAR aligner. Gigascience 7,. 


\section{Supplemental Material}

Supplementary Table 1: Supp table 1.xlsx

Column legend:

asmFC18: Fold changes of genes that were significantly assigned to atrial siphon muscle cells at $18 \mathrm{hpf}$ in scRNA-seq

fhpFC18: Fold changes of genes that were significantly assigned to first heart precursor cells at 18 hpf in scRNA-seq

shpFC18: Fold changes of genes that were significantly assigned to first second precursor cells at $18 \mathrm{hpf}$ in scRNA-seq

asmFC20: Fold changes of genes that were significantly assigned to atrial siphon muscle cells at 20 hpf in scRNA-seq

fhpFC20: Fold changes of genes that were significantly assigned to first heart precursor cells at 20 hpf in scRNA-seq

shpFC20: Fold changes of genes that were significantly assigned to first second precursor cells at 20 hpf in scRNA-seq

Supplementary Table 2: Supp Table 2

\begin{tabular}{|l|l|l|}
\hline Hours post fertilization (hpf) & $\begin{array}{l}\text { FABA Stage (Hotta et al., 2007; Hotta } \\
\text { et al., 2020) }\end{array}$ & Developmental Stage \\
\hline 12 & Stage 23 & late tailbud I \\
\hline 15 & Stage 24/25 & late tailbud II-III \\
\hline 18 & Stage 26/27 & hatching larva \\
\hline 20 & Stage 28 & early swimming larva \\
\hline 26 & Stage 30 & early swimming larva \\
\hline
\end{tabular}

Supplementary Table 3: Supp Table 3

Comprehensive list of Ciona proteins that have recognized PA-domains.

ENSCINPoooooo31058 maps to 2 KH IDs.

\begin{tabular}{|c|c|c|c|c|c|c|}
\hline ENSEMBLID & GeneID & $\begin{array}{l}\text { TranscriptI } \\
\text { D }\end{array}$ & KHID & KYID & Gene Name & $\begin{array}{l}\text { Best } 3 \text { Human } \\
\text { Orthologues }\end{array}$ \\
\hline $\begin{array}{l}\text { ENSCINPoooo } \\
0018401\end{array}$ & $\begin{array}{l}\text { ENSCINGoo } \\
\text { ooo009069 }\end{array}$ & $\begin{array}{l}\text { ENSCINTOOO } \\
\text { ooo18401 }\end{array}$ & $\begin{array}{l}\text { KH2O13:KH. } \\
\text { S215.3 }\end{array}$ & $\begin{array}{l}\text { KY2019:KY.C } \\
\text { hr13.453 }\end{array}$ & EDEM2/3 & $\begin{array}{l}\text { EDEM1; } \\
\text { EDEM2; EDEM3 }\end{array}$ \\
\hline \multirow[t]{2}{*}{$\begin{array}{l}\text { ENSCINPoooo } \\
\text { o031058 }\end{array}$} & $\begin{array}{l}\text { ENSCINGoo } \\
\text { oooo21112 }\end{array}$ & \begin{tabular}{|l} 
ENSCINTOOO \\
ooo31264
\end{tabular} & $\begin{array}{l}\text { KH2O13:KH. } \\
\text { C14.482 }\end{array}$ & $\begin{array}{l}\text { KY2019:KY.C } \\
\text { hr14.219 }\end{array}$ & $\begin{array}{l}\text { KH2O13:KH.C14. } \\
482\end{array}$ & \\
\hline & & & $\begin{array}{l}\text { KH2O13:KH. } \\
\text { C8.229 }\end{array}$ & $\begin{array}{l}\text { KY2019:KY.C } \\
\text { hr8.448 }\end{array}$ & NAALAD2 & $\begin{array}{l}\text { FOLH1; } \\
\text { NAALAD2; } \\
\text { NAALADL1 }\end{array}$ \\
\hline
\end{tabular}




\begin{tabular}{|c|c|c|c|c|c|c|}
\hline $\begin{array}{l}\text { ENSCINPoooo } \\
\text { o010505 }\end{array}$ & $\begin{array}{l}\text { ENSCINGoo } \\
\text { ooooo5093 }\end{array}$ & $\begin{array}{l}\text { ENSCINTOOO } \\
\text { oo010505 }\end{array}$ & $\begin{array}{l}\text { KH2O13:KH. } \\
\mathrm{C} 14.568\end{array}$ & $\begin{array}{l}\text { KY2019:KY.C } \\
\text { hr14.218 }\end{array}$ & GTF2E2 & T2EB \\
\hline $\begin{array}{l}\text { ENSCINPoooo } \\
\text { oo34768 }\end{array}$ & $\begin{array}{l}\text { ENSCINGoo } \\
\text { oooo18380 }\end{array}$ & $\begin{array}{l}\text { ENSCINTOoo } \\
\text { ooo3666o }\end{array}$ & $\begin{array}{l}\text { KH2O13:KH. } \\
\text { C11.425 }\end{array}$ & $\begin{array}{l}\text { KY2019:KY.C } \\
\text { hr11.1091 }\end{array}$ & VPS70 & $\begin{array}{l}\text { FOLH1; } \\
\text { NAALAD2; } \\
\text { NAALADL1 }\end{array}$ \\
\hline $\begin{array}{l}\text { ENSCINPOOOO } \\
\text { oo14713 }\end{array}$ & $\begin{array}{l}\text { ENSCINGoo } \\
\text { ooooo7174 }\end{array}$ & $\begin{array}{l}\text { ENSCINTOOO } \\
\text { ooo14713 }\end{array}$ & $\begin{array}{l}\text { KH2O13:КH. } \\
\text { C7.451 }\end{array}$ & $\begin{array}{l}\text { KY2019:KY.C } \\
\text { hr7.828 }\end{array}$ & $\begin{array}{l}\text { KH2O13:KH.C7.4 } \\
\text { 51_FOLH1 }\end{array}$ & $\begin{array}{l}\text { FOLH1; } \\
\text { NAALAD2; } \\
\text { NAALADL1 }\end{array}$ \\
\hline $\begin{array}{l}\text { ENSCINPoooo } \\
\text { oo11038 }\end{array}$ & $\begin{array}{l}\text { ENSCINGoo } \\
\text { ooooo5372 }\end{array}$ & $\begin{array}{l}\text { ENSCINTOOO } \\
\text { ooo11038 }\end{array}$ & $\begin{array}{l}\text { KH2O13:KH. } \\
\text { S346.8 }\end{array}$ & $\begin{array}{l}\text { KY2019:KY.C } \\
\text { hr2.2186 }\end{array}$ & $\mathrm{C}_{35} \mathrm{C}_{5.2}$ & $\begin{array}{l}\text { FOLH1; } \\
\text { NAALAD2; } \\
\text { NAALADL1 }\end{array}$ \\
\hline $\begin{array}{l}\text { ENSCINPoooo } \\
\text { Oo23283 }\end{array}$ & $\begin{array}{l}\text { ENSCINGoo } \\
\text { oooo12489 }\end{array}$ & $\begin{array}{l}\text { ENSCINTooo } \\
\text { ooo23529 }\end{array}$ & $\begin{array}{l}\text { KH2O13:KH. } \\
\text { C1.401 }\end{array}$ & $\begin{array}{l}\text { KY2019:KY.C } \\
\text { hr1.2172 }\end{array}$ & RNF13 & $\begin{array}{l}\text { RN167; RNF13; } \\
\text { ZNRF4 }\end{array}$ \\
\hline \begin{tabular}{|l|} 
ENSCINPoooo \\
oo21924
\end{tabular} & $\begin{array}{l}\text { ENSCINGoo } \\
\text { oooo11483 }\end{array}$ & $\begin{array}{l}\text { ENSCINTooo } \\
\text { ooo } 22170\end{array}$ & $\begin{array}{l}\text { KH2O13:KH. } \\
\text { C2.730 }\end{array}$ & $\begin{array}{l}\text { KY2019:KY.C } \\
\text { hr2.1035 }\end{array}$ & $\begin{array}{l}\text { KH2O13:KH.C2.7 } \\
\text { 30_RNF149 }\end{array}$ & $\begin{array}{l}\text { RNF130; } \\
\text { RNF149; } \\
\text { RNF15O }\end{array}$ \\
\hline $\begin{array}{l}\text { ENSCINPOOOO } \\
\text { oo30411 }\end{array}$ & $\begin{array}{l}\text { ENSCINGoo } \\
\text { oooo11483 }\end{array}$ & $\begin{array}{l}\text { ENSCINTOOO } \\
\text { ooo35820 }\end{array}$ & $\begin{array}{l}\text { KH2O13:KH. } \\
\text { C11.361 }\end{array}$ & $\begin{array}{l}\text { KY2019:KY.C } \\
\text { hr11.1266 }\end{array}$ & RNF215 & $\begin{array}{l}\text { GOLI; RN15O; } \\
\text { RN215 }\end{array}$ \\
\hline $\begin{array}{l}\text { ENSCINPoooo } \\
\text { oo22045 }\end{array}$ & $\begin{array}{l}\text { ENSCINGoo } \\
\text { oooo11573 }\end{array}$ & $\begin{array}{l}\text { ENSCINTooo } \\
\text { ooo22291 }\end{array}$ & $\begin{array}{l}\text { KH2O13:KH. } \\
\text { C2.994 }\end{array}$ & $\begin{array}{l}\text { KY2019:KY.C } \\
\text { hr2.519 }\end{array}$ & $\begin{array}{l}\text { KH2O13:KH.C2.9 } \\
\text { 94_RNF149 }\end{array}$ & $\begin{array}{l}\text { RNF130; } \\
\text { RNF148; } \\
\text { RNF149 }\end{array}$ \\
\hline $\begin{array}{l}\text { ENSCINPoooo } \\
\text { oo30577 }\end{array}$ & $\begin{array}{l}\text { ENSCINGoo } \\
\text { oooo23464 }\end{array}$ & $\begin{array}{l}\text { ENSCINTOoo } \\
\text { ooo30308 }\end{array}$ & $\begin{array}{l}\text { KH2013:KH. } \\
\text { C4.37 }\end{array}$ & $\begin{array}{l}\text { KY2019:KY.C } \\
\text { hr4.430 }\end{array}$ & PRADC1 & PADC1 \\
\hline
\end{tabular}

Supplementary Table 4: Genes tested and primers used to construct sgRNAs to validate post-transcriptional regulators detected by scRNA-seq.

\begin{tabular}{|l|l|l|l|}
\hline $\begin{array}{l}\text { Transcript (KH) } \\
\text { ID }\end{array}$ & Gene Name & Oligo name & sequence 5'-3' \\
\hline KH2013:KH.C2.994 & Rnf149-r & sgRNF_2_fw & ggatggtggacctgacacatgtttaagagctatgctggaaacag \\
\hline KH2013:KH.C2.994 & Rnf149-r & sgRNF_2_rev & atgtgtcaggtccaccatccatctataccatcggatgccttc \\
\hline KH2013:KH.C2.994 & Rnf149-r & sgRNF_4_fw & ggagttacactgttaagaaggtttaagagctatgctggaaacag \\
\hline $\begin{array}{l}\text { KH2013:KH.C2.994 } \\
\text { Rnf149-r }\end{array}$ & sgRNF_4_rev & cttcttaacagtgtaactccatctataccatcggatgccttc \\
\hline $\begin{array}{l}\text { KH2013:KH.C10.25 } \\
\text { O RBFOX1/2/3 }\end{array}$ & ggRBFOX_1_F & ggagttctgcatgtaggtgggtttaagagctatgctggaaacag \\
\hline $\begin{array}{l}\text { KH2013:KH.C10.25 } \\
\text { o }\end{array}$ & RBFOX1/2/3 & sgRBFOX_1_R & ccacctacatgcagaactccatctataccatcggatgccttc \\
\hline $\begin{array}{l}\text { KH2013:KH.C10.25 } \\
\text { O }\end{array}$ & RBFOX1/2/3 & sgRBFOX_4_F & ggcttgaacgaattcagctggtttaagagctatgctggaaacag \\
\hline $\begin{array}{l}\text { KH2013:KH.C10.25 } \\
\text { O }\end{array}$ & RBFOX1/2/3 & sgRBFOX_4_R & cagctgaattcgttcaagccatctataccatcggatgccttc \\
\hline
\end{tabular}




\begin{tabular}{|c|c|c|c|}
\hline KH2O13:KH.C7.2O5 & ASB2 & SgASB_1_F & gaaagtttggaggaatcgctgtttaagagctatgctggaaacag \\
\hline KH2O13:KH.C7.205 & ASB2 & SgASB_1_R & agcgattcctccaaactttcatctataccatcggatgccttc \\
\hline KH2O13:KH.C7.2O5 & $\mathrm{ASB} 2$ & sgASB_2_F & gggtggcataagtgatgagtgtttaagagctatgctggaaacag \\
\hline KH2O13:KH.C7.2O5 & ASB2 & SgASB_2_R & actcatcacttatgecacccatctataccatcggatgecttc \\
\hline KH2O13:KH.C7.2O5 & ASB2 & sgASB_6_F & gacctacgtaacatcgattggtttaagagctatgctggaaacag \\
\hline KH2O13:KH.C7.2O5 & ASB2 & sgASB_6_R & caatcgatgttacgtaggtcatctataccatcggatgccttc \\
\hline KH2O13:KH.L9.27 & $\mathrm{RBM} 24 / 38$ & sgRBM_1_F & gtacaccaagatattcgtgggtttaagagctatgctggaaacag \\
\hline KH2O13:KH.L9.27 & $\mathrm{RBM} 24 / 38$ & sgRBM_1_R & ccacgaatatcttggtgtacatctataccatcggatgccttc \\
\hline KH2013:KH.L9.27 & $\mathrm{RBM} 24 / 38$ & sgRBM_6_F & gatccgaacceggtgatcgagtttaagagctatgctggaaacag \\
\hline KH2O13:KH.L9.27 & $\mathrm{RBM} 24 / 38$ & sgRBM_6_R & tcgatcaccgggttcggatcatctataccatcggatgccttc \\
\hline KH2O13:KH.S115.4 & QKI & sgQKI_5_F & gcctgctggtggtagttatggtttaagagctatgctggaaacag \\
\hline KH2O13:KH.S115.4 & QKI & sgQKI_5_R & cataactaccaccagcaggcatctataccatcggatgecttc \\
\hline KH2O13:KH.S115.4 & QKI & sgQKI_6_F & gagcgccgttggtggtaggcgtttaagagctatgctggaaacag \\
\hline KH2O13:KH.S115.4 & QKI & sgQKI_6_R & gcctaccaccaacggegctcatctataccatcggatgccttc \\
\hline KH2O13:KH.C11.417 & NOVA1/2 & Nova1.2_F & gacaggcctacacggcacagtttaagagctatgctggaaacag \\
\hline KH2O13:KH.C11.417 & NOVA1/2 & Nova1.2_R & tgtgccgtgtaggectgtcatctataccatcggatgcettc \\
\hline KH2O13:KH.C11.417 & NOVA1/2 & Nova2.1_F & gaagaatgagctggccegggtttaagagctatgctggaaacag \\
\hline KH2O13:KH.C11.417 & NOVA1/2 & Nova2.1_R & ccgggccagctcattcttcatctataccatcggatgccttc \\
\hline KH2O13:KH.C11.417 & NOVA1/2 & Nova2.3_F & gtaccggggtacgctgcgggtttaagagctatgctggaaacag \\
\hline KH2O13:KH.C11.417 & NOVA1/2 & Nova2.3_R & ccgcagcgtaccceggtacatctataccatcggatgccttc \\
\hline KH2O13:KH.C2.730 & RNF150 & sgRNF150_2_F & gtgttgtcacatggaattatgtttaagagctatgctggaaacag \\
\hline KH2O13:KH.C2.730 & RNF150 & sgRNF150_2_R & ataattccatgtgacaacacatctataccatcggatgccttc \\
\hline KH2O13:KH.C2.730 & RNF150 & sgRNF150_3_F & gggcttgctttggtttcacggtttaagagctatgctggaaacag \\
\hline KH2O13:KH.C2.730 & RNF150 & SgRNF15O_3_R & cgtgaaaccaaagcaagcccatctataccatcggatgccttc \\
\hline KH2O13:KH.C2.730 & RNF150 & sgRNF150_5_F & gtagagacaatgagccatgcgtttaagagctatgctggaaacag \\
\hline KH2O13:KH.C2.730 & RNF150 & sgRNF150_5_R & gcatggctcattgtctctacatctataccatcggatgccttc \\
\hline
\end{tabular}

Supplementary Table 5: Tyr $r^{\text {CRISPR }}$ vs. Rnf149-r ${ }^{\text {CRISPR }}$ RNA-seq gene list with log fold-change (logFC), p-value (PValue) and false discovery rate (FDR) values.

toptags_rnfko_KH_UniqueName.xlsx

Column legend:

logFC: Log fold change, $\log$ CPM: Log counts per million, FDR: False Discovery Rate 
bioRxiv preprint doi: https://doi.org/10.1101/2022.01.07.475354; this version posted January 7, 2022. The copyright holder for this preprint (which was not certified by peer review) is the author/funder, who has granted bioRxiv a license to display the preprint in perpetuity. It is made available under aCC-BY-NC-ND 4.0 International license. 


\section{Figure legends}

\section{Figure 1: Rnfi 49-r $^{\mathrm{CRISPR}}$ causes ASM migration defects.}

a) Schematic of Ciona development showing asymmetric cell divisions and resulting cell fates of the cardiopharyngeal mesoderm (CPM). Stages are set according to Hotta et al. (2007) with hours post fertilization (hpf) at $18^{\circ} \mathrm{C}$ (Supp table 2). Anterior tail muscle (ATM, gray), trunk ventral cell (TVC, green), secondary TVC (STVC, yellow), first heart precursor (FHP, red), second heart precursor (SHP, orange), atrial siphon precursor cells (ASMF, blue). Dashed lines indicate the ventral midline.

b) Schematic representation of phenotypes scored in Figure 1c.

c) $\mathrm{Tyr}^{\mathrm{CRISPR}}$ used as control. Cardiopharyngeal lineage are marked by mCherry and GFP driven by Mesp. H2B::GFP (green) and hCD4::mCherry (red) accumulate in the nuclei and at the cell membrane, respectively. Arrow indicates the heart progenitors and the open arrow indicates the ASM ring.

d) Histogram with phenotype proportions. Neurog ${ }^{\text {CRISPR }}$ are used as control, a gene that is known to be inactive in the cardiopharyngeal lineage. First 5 genes scored compared to Neurog $^{\mathrm{CRISPR}}$ are not significant per Fisher exact test while $R n f 149-r^{\mathrm{CRISPR}}$ is significant with $p$-value<0.0001. Experiments are performed in biological replicates and " $n=$ " represents the total numbers of individual halves scored per condition. Error bars represent 95\% Wilson method of confidence interval for proportions.

e) Corresponding histogram with phenotype proportions. Experiments are performed in biological replicates. " $n=$ " represents the total numbers of individual halves scored per condition. Error bars represent 95\% Wilson method of confidence interval for proportions.

\section{Figure 2: $R$ nfi49-r ${ }^{\text {CRISPR }}$ causes behavioral defects in the cardiopharyngeal lineage.}

a) In situ hybridization using an $E b f$ probe in green. $T y r^{\text {CRISPR }}$ used as control. Cardiopharyngeal lineage are marked by mCherry driven by Mesp and revealed by mCherry antibody in red. H2B::mCherry accumulates in the nuclei. Scale bar is $50 \mu \mathrm{m}$. Arrows mark ASMFs.

b) Corresponding histogram with phenotype proportions. " $n=$ " represents the total numbers of individual halves scored per condition. Error bars represent 95\% Wilson method of confidence interval for proportions.

\section{Figure 3: Rnf149-r acts in parallel to the FGF/MAPK pathway.}

a) Schematic representation of the FGF/MAPK pathway.

b) In situ hybridization using an Ebf probe. Tyr ${ }^{\mathrm{CRISPR}}$ are used as control. Cardiopharyngeal lineage is marked by mCherry and LacZ driven by Mesp and FoxF, revealed by mCherry and Beta-gal antibodies in magenta and cyan, respectively. H2B::mCherry and hCD4::mCherry (cyan) accumulate in the nuclei and at the cell membrane, respectively. Dashed lines indicate the ventral midline. Arrows mark ASMFs.

c) Corresponding histogram with phenotype proportions. "n=" represents the total numbers of individual halves scored per condition. Error bars represent 95\% Wilson method of confidence interval for proportions.

Figure 4: Rnfi49-r has novel targets contributing to the cell fate choices in the cardiopharyngeal lineage. 
a) Volcano plot showing significantly upregulated and downregulated genes upon $R n f 149-r^{\mathrm{CRISPR}}$ compared to control ( y $^{\mathrm{CRISPR}}$ ) cardiopharyngeal lineage cells in red (FDR<0.05). Genes shown in black are well-studied ASM-specific markers (Ebf1/2/3/4, Htr7 and Tbx1/1O) and our target gene, Rnf149-r. Experiments are done in triplicates.

b) Log fold-change correlations between MAPK abolishment (Hand-r $>F g f r^{D N}$ ) (Wang et al., 2019) and $R n f 149-r^{\text {CRISPR }}$, using only differentially expressed genes in either conditions. Genes shown in red are differentially expressed in the $R n f 149-r^{\mathrm{CRISPR}}$ condition. $\mathrm{R}$ represents the Pearson correlation coefficient.

c) Euler diagram showing overlaps of differentially expressed gene groups in $R n f 149^{-r^{C R I S P R}}$ and Hand- $r>F g f^{D N}$. Mutual enrichment p-value, calculated using Fisher's exact test, is $4.7 \mathrm{e}-08$. Odds ratio is calculated to be 3.3 .

d) Proposed model of Rnf149-r's effect on regulation of the cardiopharyngeal lineage in Ciona. 


\section{Supplemental figure legends}

\section{Figure S1: FISH validation of the expression for candidate genes.}

First row is predicted heart genes, second and third row predicted ASM genes. mRNAs are visualized by whole mount fluorescent in situ hybridization (green). Nuclei of cells are marked by Mesp>nls::LacZ and revealed by anti beta-galactosidase antibody (red). Mesp $>$ hCD4::mCherry accumulates in the cell membrane and is revealed by anti mCherry antibody (blue). White line indicates the midline.

\section{Figure S2: FISH validation and violin plots of the expression for $\operatorname{Rnf149}$ at different developmental time points.}

a) mRNAs are visualized by whole mount fluorescent in situ hybridization (green). Cells are marked by Mesp $>$ mCherry. b) Violin plots represent the distribution of the expression of indicated genes in defined cell clusters (Wang et al., 2019). Each cell is represented by a black dot. On the x-axis, the numbers indicate hours post fertilization (hpf). Scale bar, $50 \mu \mathrm{m}$.

Figure S3: Both sgRNAs used to generate Rnf149-r $^{\text {CRISPR }}$ contribute to the phenotype. a) Schematic of the Rnf149-r gene and the positions of the two sgRNAs used. b) Histogram with phenotype proportions. " $n=$ " represents the total numbers of individual halves scored per condition. Error bars represent 95\% Wilson method of confidence interval for proportions.

Figure S4: $R$ nf149-r ${ }^{\text {CRISPR }}$ does not alter the TVC marker Hand-r expression at 12 hpf. Left panel shows the in situ hybridization against a Hand-r probe in green. Ty ${ }^{\text {CRISPR }}$ used as control. Cardiopharyngeal lineage marked by mCherry driven by Mesp and revealed by mCherry antibody in red. H2B::mCherry accumulates in the nuclei. Scale bar, $50 \mu \mathrm{m}$. Right panel shows the corresponding histogram with phenotype proportions. " $n=$ " represents the total numbers of individual halves scored per condition.

Figure S5: There are 11 PA domain-containing genes in the Ciona genome. PA domains shown in light blue, RING domains shown in green, Zn-independent exopeptidase domains shown in yellow, transferrin receptor-like dimerization domains shown in red and seven-hairpin glycosidase domain shown in purple.

Figure S6: $\operatorname{Rnf15}^{\text {CRISPR }}$ did not result in significant phenotypic deformities at 26 hpf. Histogram with phenotype proportions. "n=" represents the total numbers of individual halves scored per condition.

Figure S7: The histogram for the TVC-specific FoxF enhancer labeling, FoxF $>$ LacZ , with phenotype proportions. "n=" represents the total numbers of individual halves scored per condition. Error bars represent 95\% Wilson method of confidence interval for proportions. 
bioRxiv preprint doi: https://doi.org/10.1101/2022.01.07.475354; this version posted January 7, 2022. The copyright holder for this preprint (which was not certified by peer review) is the author/funder, who has granted bioRxiv a license to display the preprint in perpetuity. It is made available under aCC-BY-NC-ND 4.0 International license.

a. Stage $22-23$

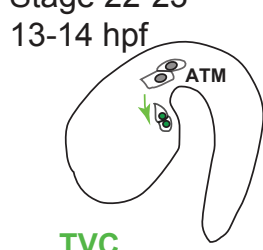

TVC

migration

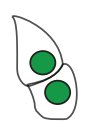

TVC

\section{4-25}

14-15 hpf

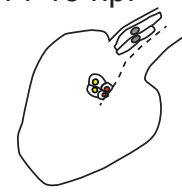

STVC

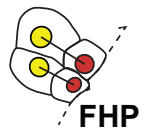

FHP

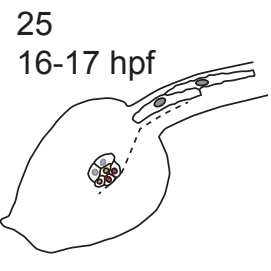

ASMF

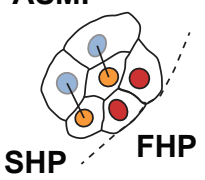

27

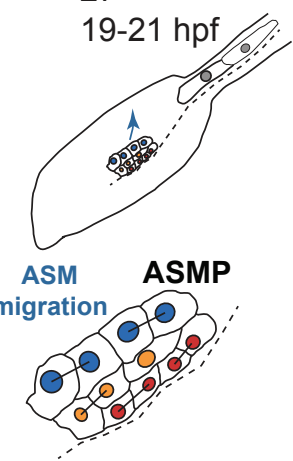

29-30

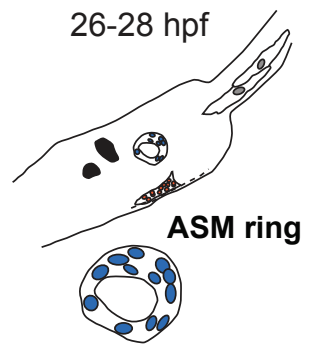

Heart b.

26 hpf
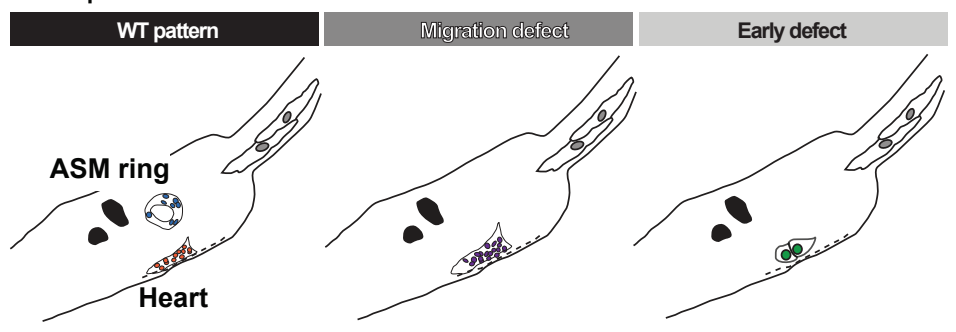

d.

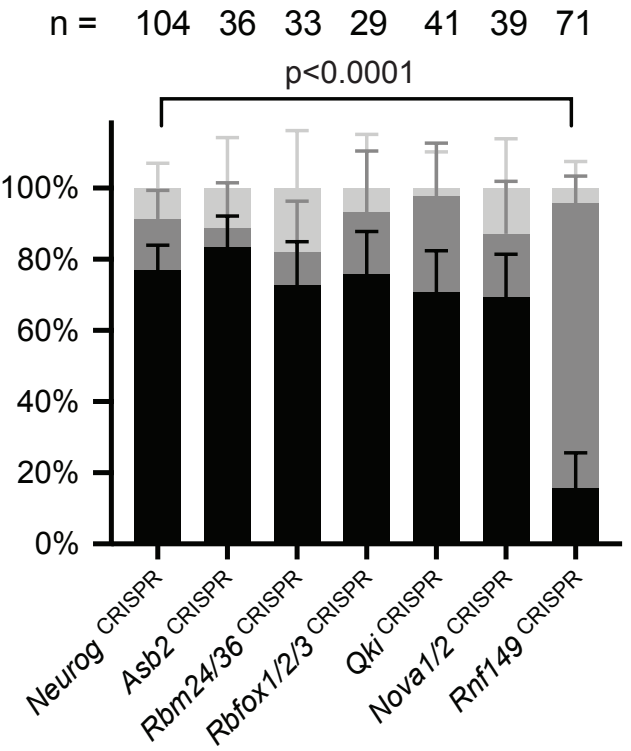

ASM phenotype $26 \mathrm{hpf}$

- WT pattern

- Migration defect

Early defect
C.

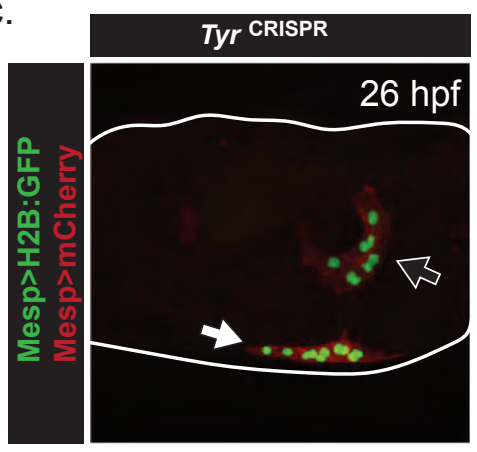

e.

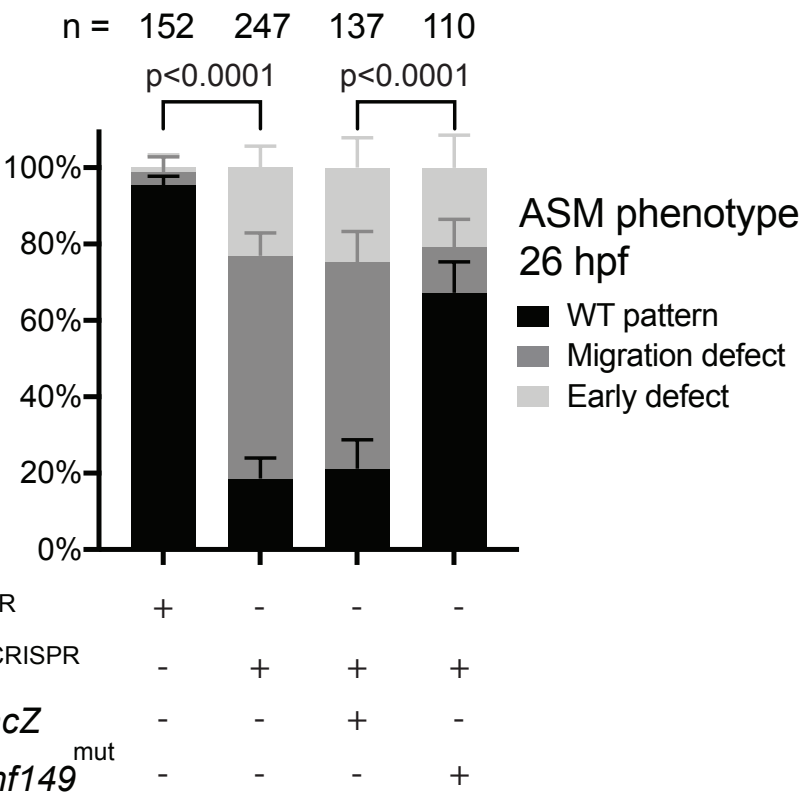


a.

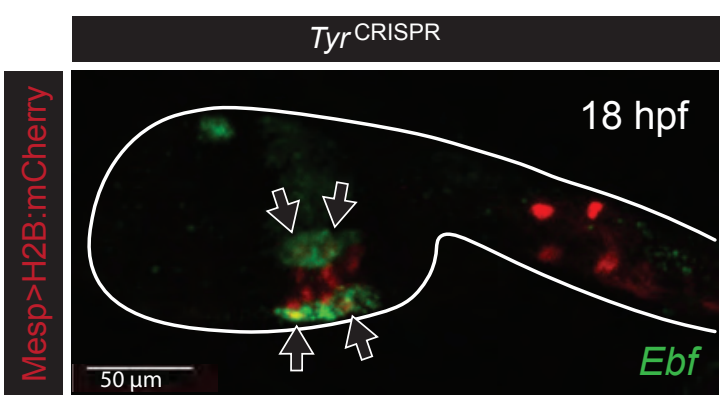

Rnf149-r CRISPR
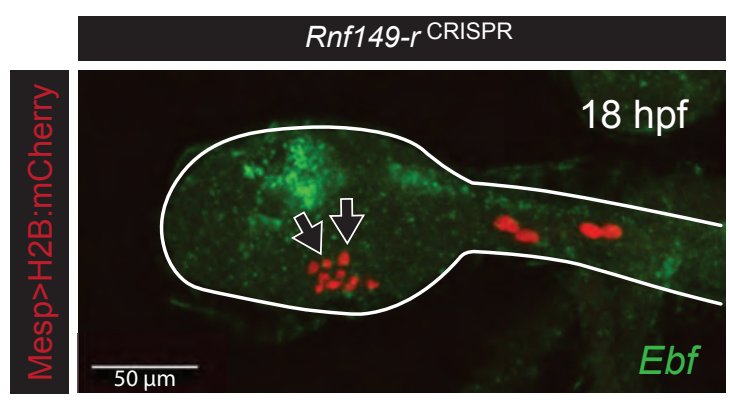

b.

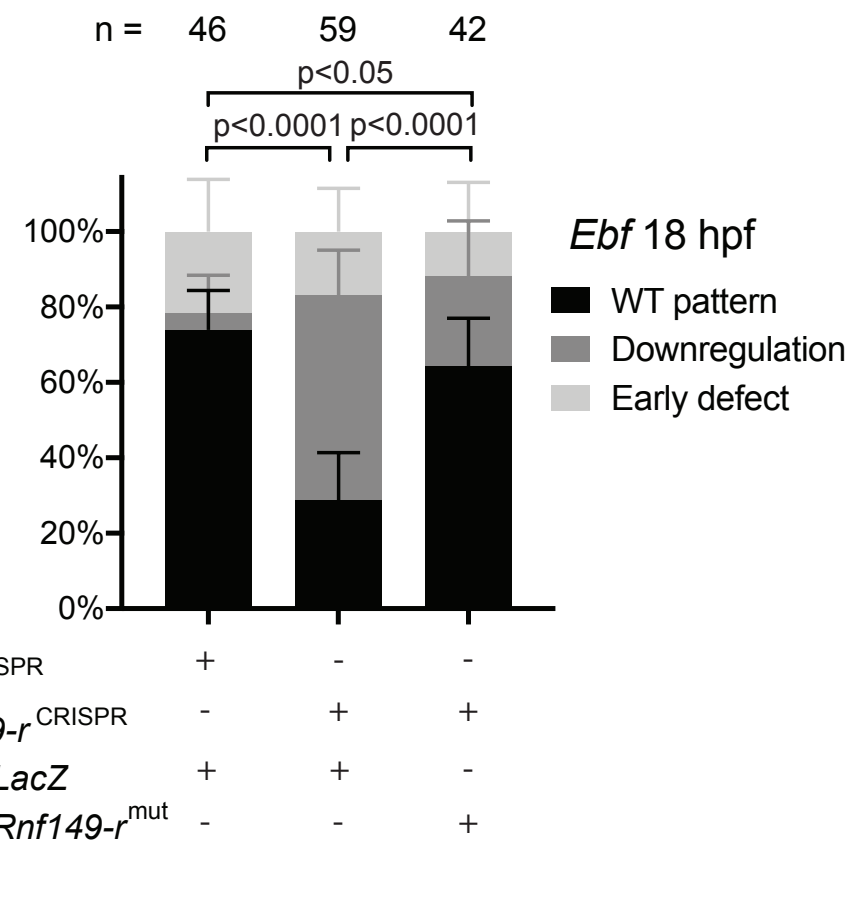

Tyr ${ }^{\text {CRISPR }}$

Rnf149-r CRISPR

Foxf $>$ LacZ

Foxf $>$ Rnf149-r ${ }^{\text {mut }}$

Figure 2. 
bioRxiv preprint doi: https://doi.org/10.1101/2022.01.07.475354; this version posted January 7, 2022. The copyright holder for this preprint (which was not certified by peer review) is the author/funder, who has granted bioRxiv a license to display the preprint in perpetuity. It is made available under aCC-BY-NC-ND 4.0 International license.

a.
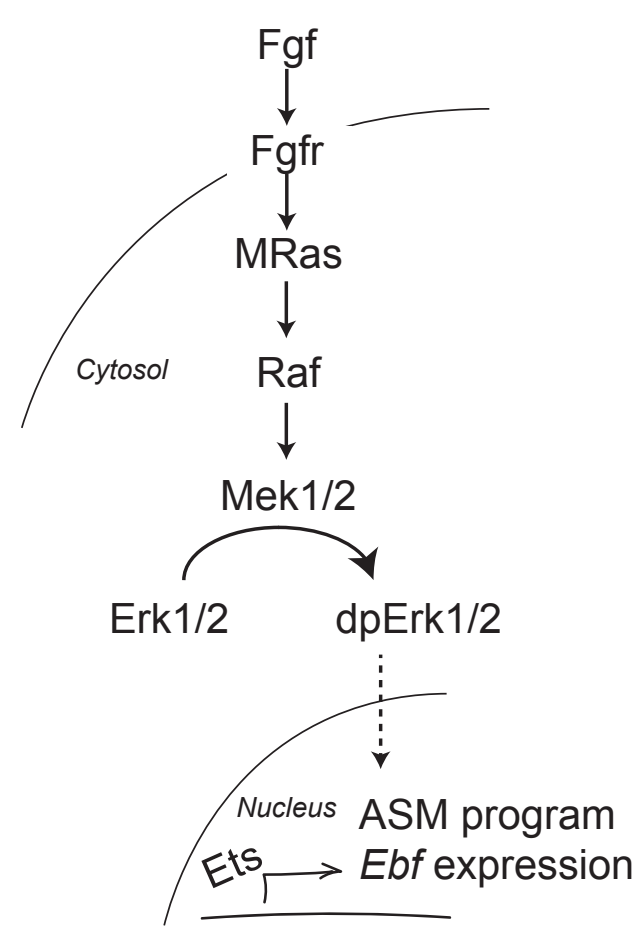

c.

$$
\begin{aligned}
& \mathrm{n}=\quad \begin{array}{llllllll}
96 & 111 & 103 & 82 & 140 & 129 & 34 & 27
\end{array} \\
& \stackrel{p<0.0001}{\longrightarrow} \quad \mathrm{p}<0.0001 \quad \mathrm{p}<0.0001 \quad \mathrm{p}<0.005
\end{aligned}
$$

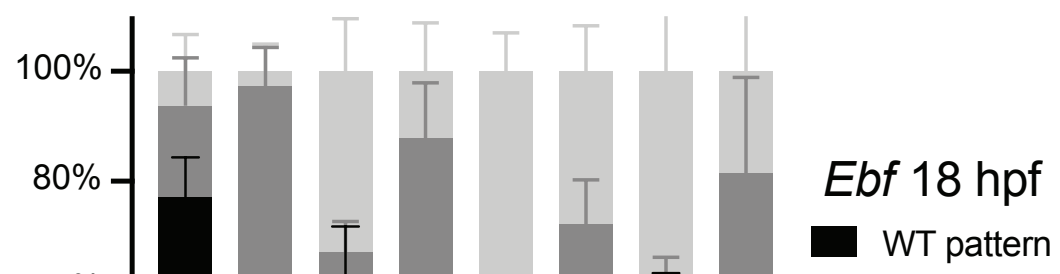

Downregulation Ectopic expression b.

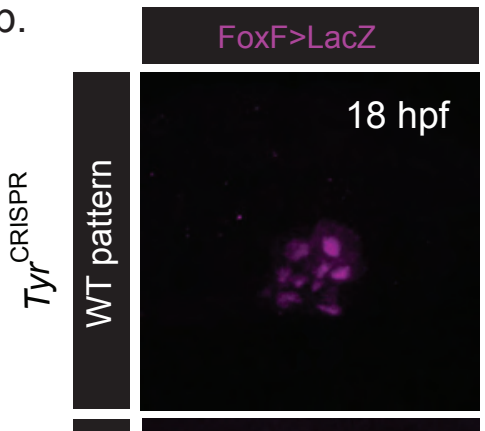

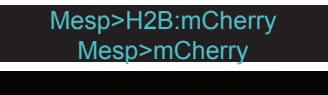
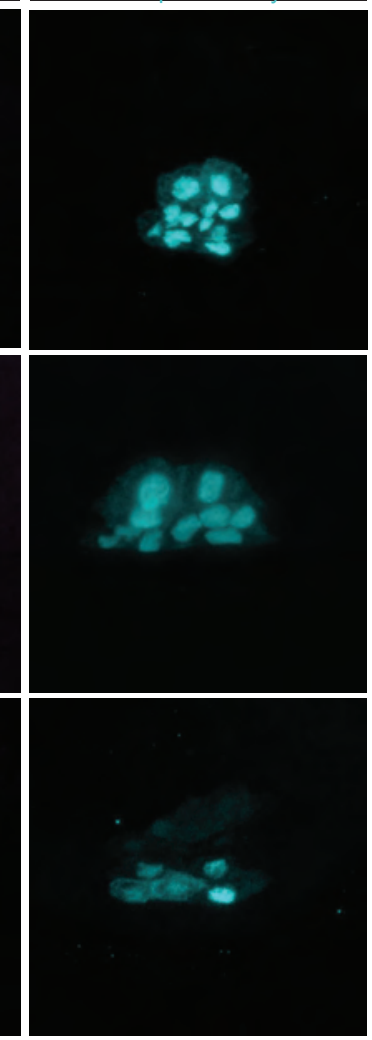
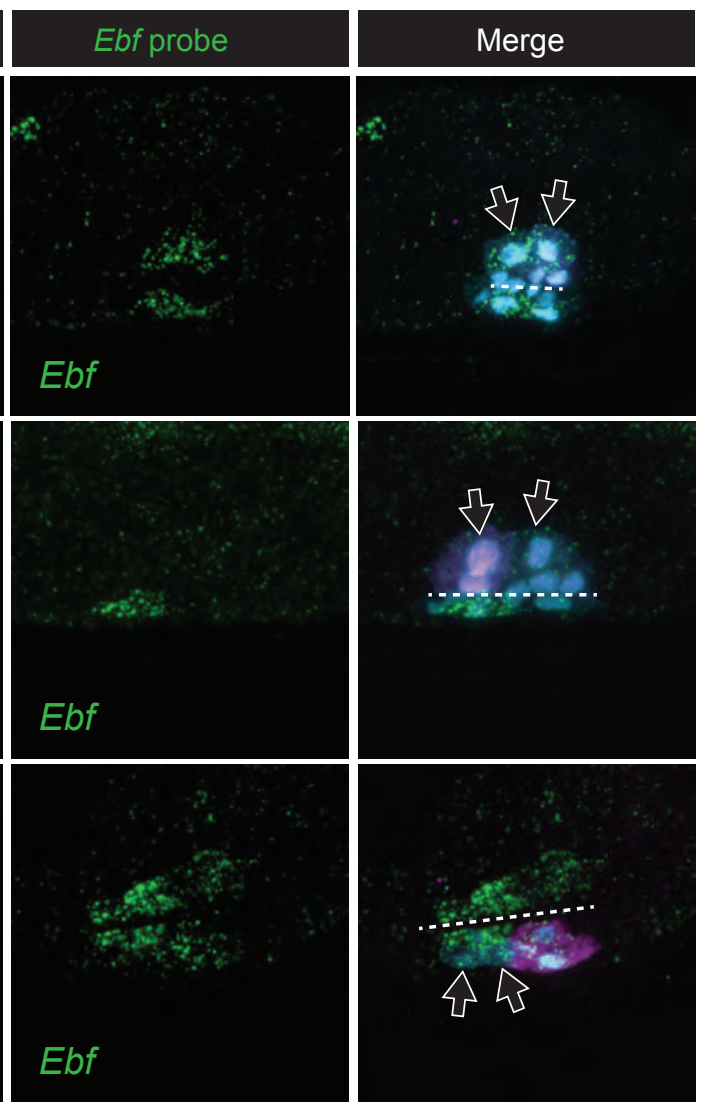

Figure 3. 
a.

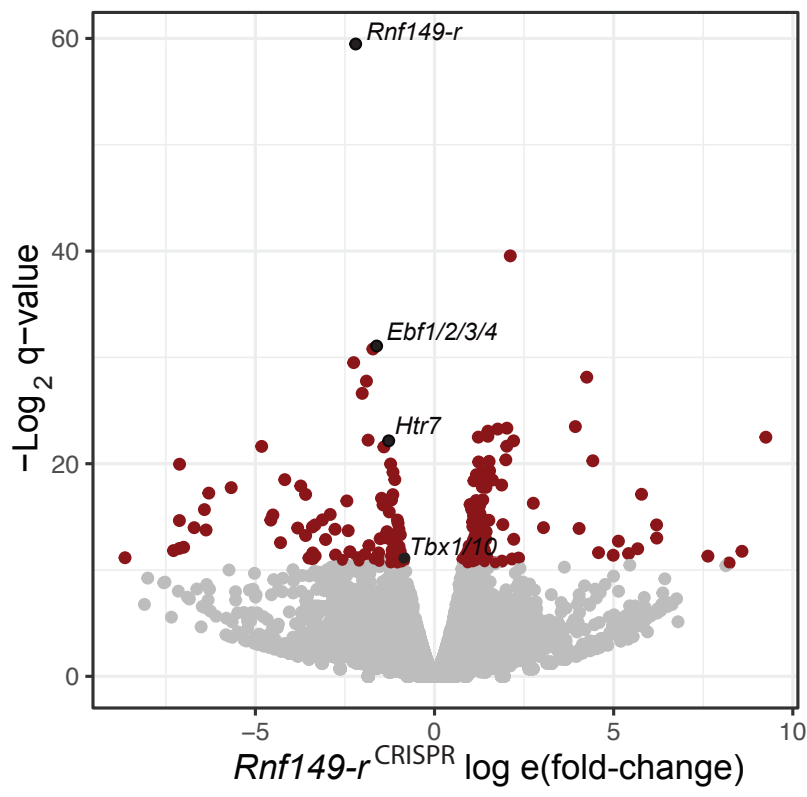

C.

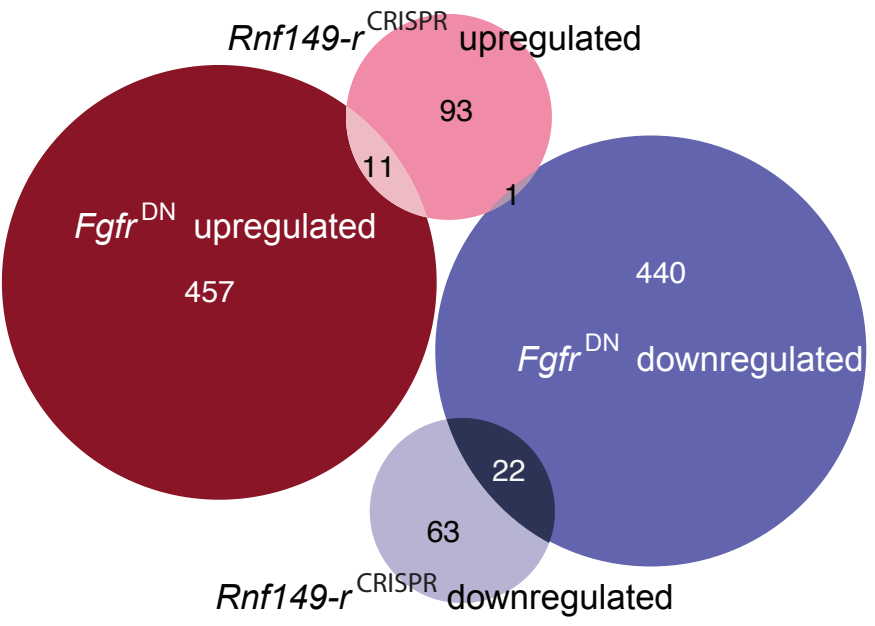

b.

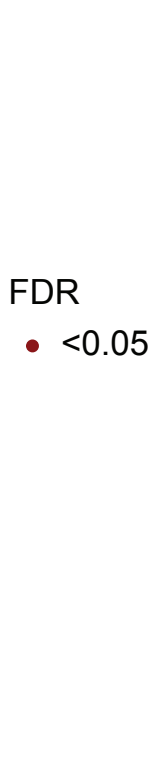

d.

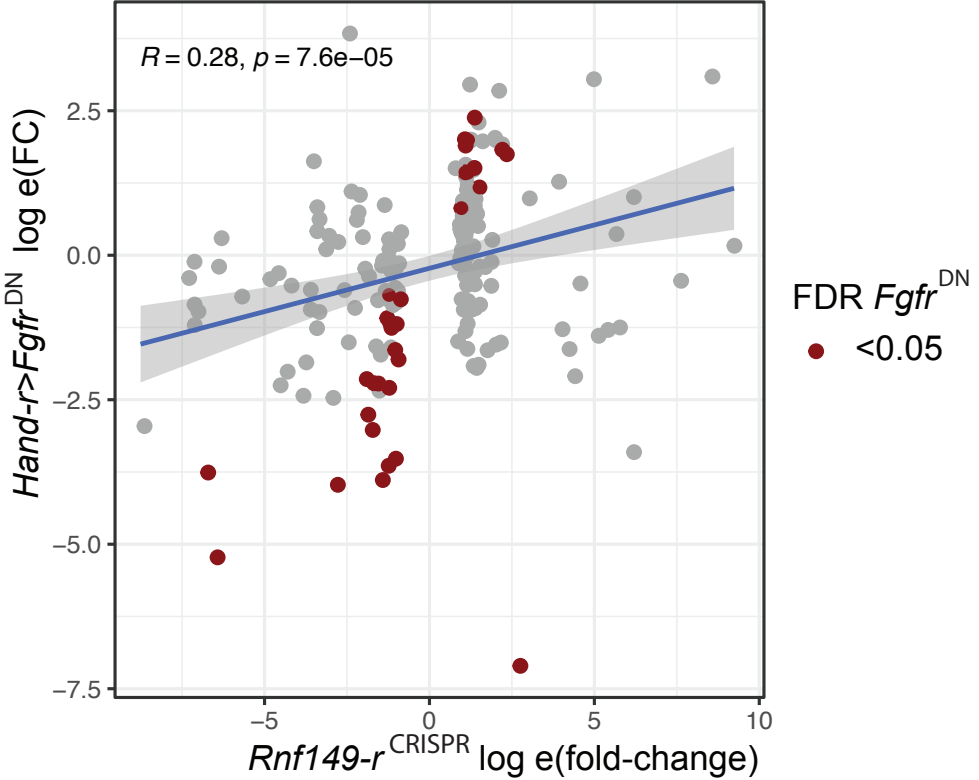

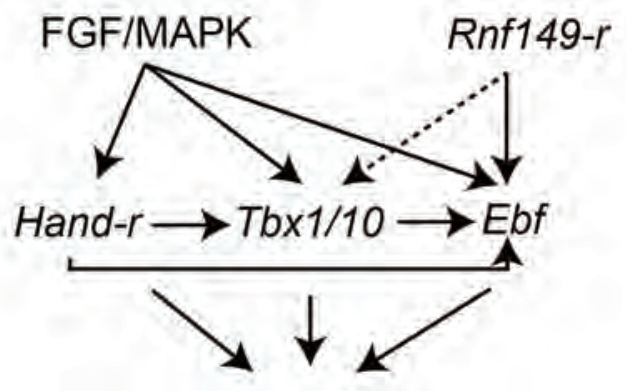

Pharyngeal muscle fate

\section{Figure 4.}


bioRxiv preprint doi: https://doi.org/10.1101/2022.01.07.475354; this version posted January 7, 2022. The copyright holder for this preprint (which was not certified by peer review) is the author/funder, who has granted bioRxiv a license to display the preprint in perpetuity. It is made available under aCC-BY-NC-ND 4.0 International license.

\section{Supplemental fig. 1}
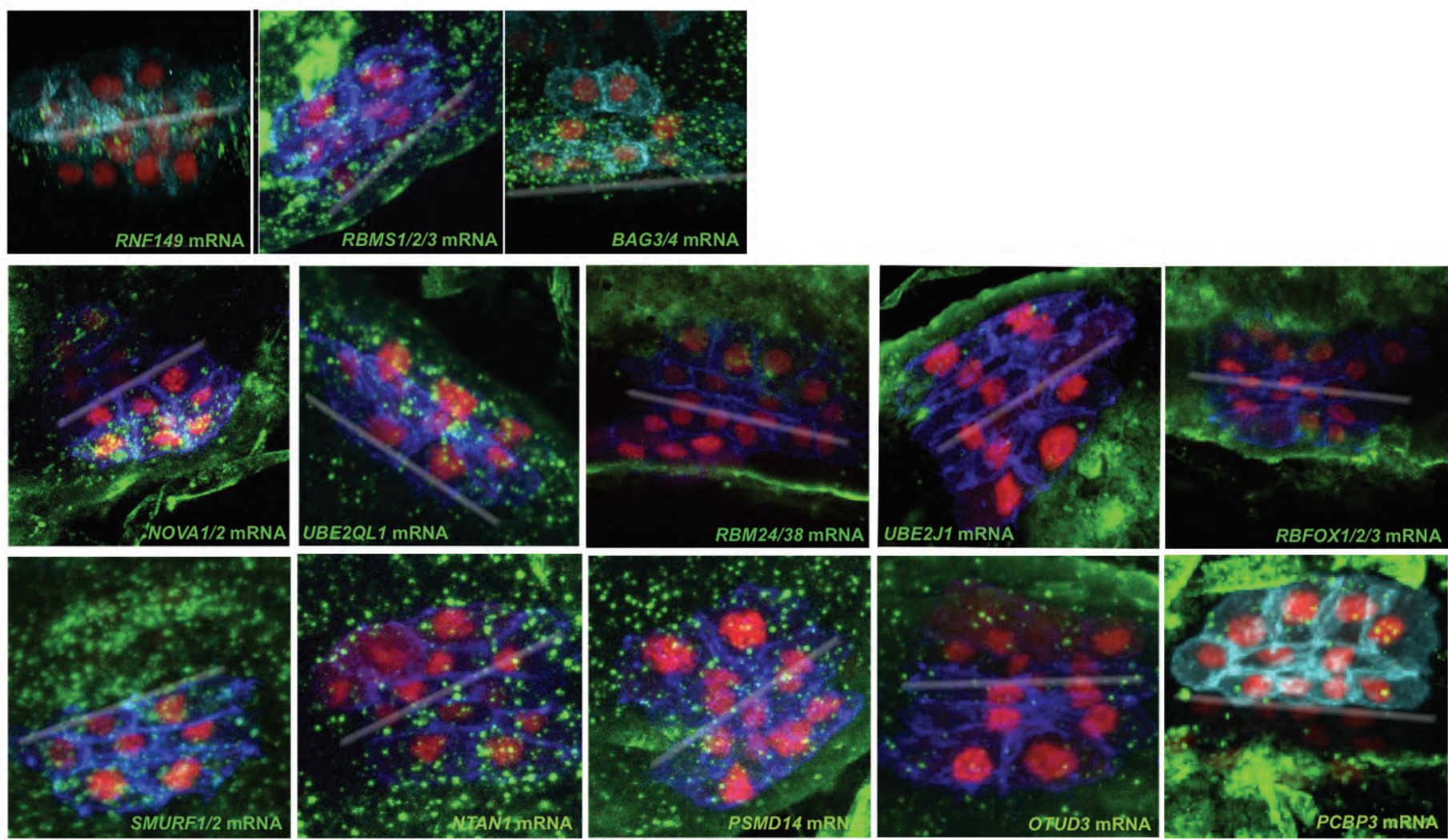


\section{Supplemental fig. 2}

a.

KH.C2.994_RNF149

exon 2

exon 1

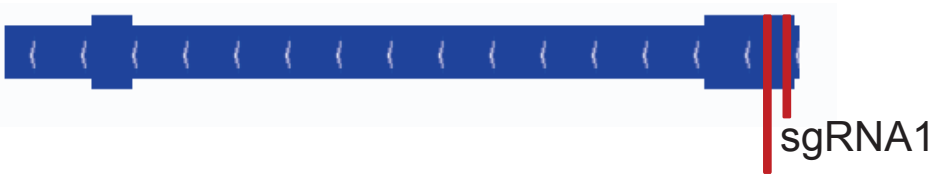

b.

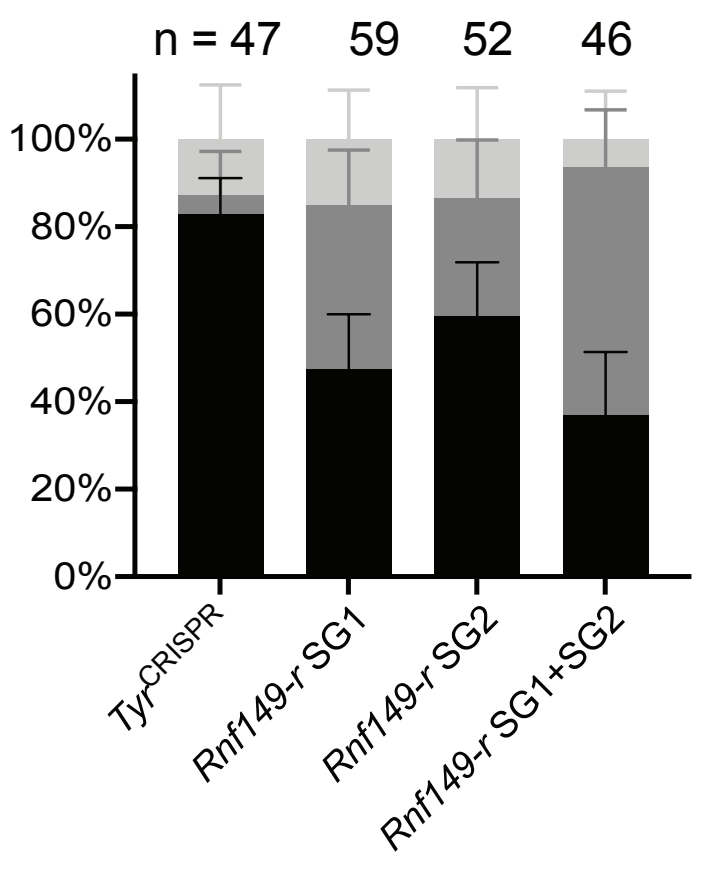

ASM phenotype 26 hpf

- WT pattern

Migration defect

Early defect 
bioRxiv preprint doi: https://doi.org/10.1101/2022.01.07.475354; this version posted January 7, 2022. The copyright holder for this preprint (which was not certified by peer review) is the author/funder, who has granted bioRxiv a license to display the preprint in perpetuity. It is made available under aCC-BY-NC-ND 4.0 International license.

\section{Supplemental fig. 3}

a.
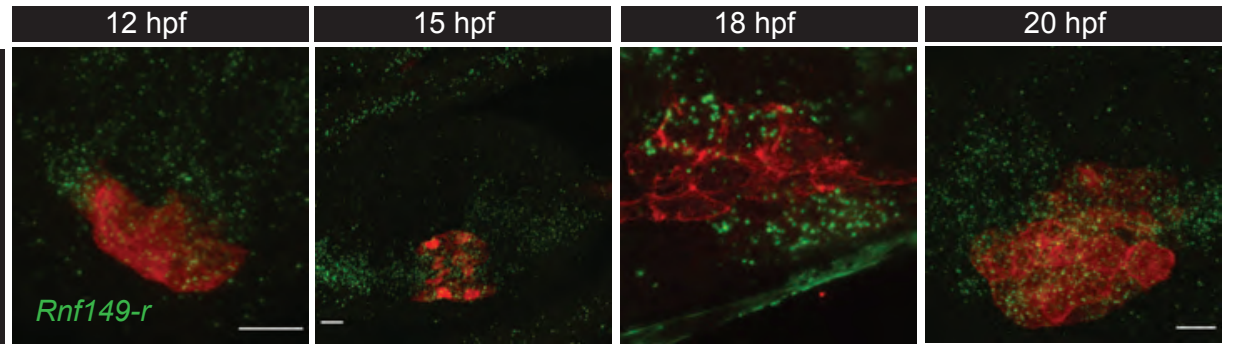

b.

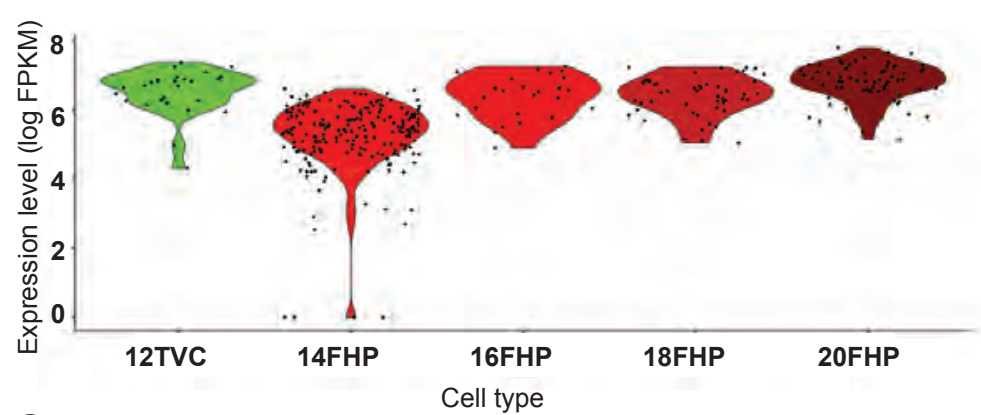

C.

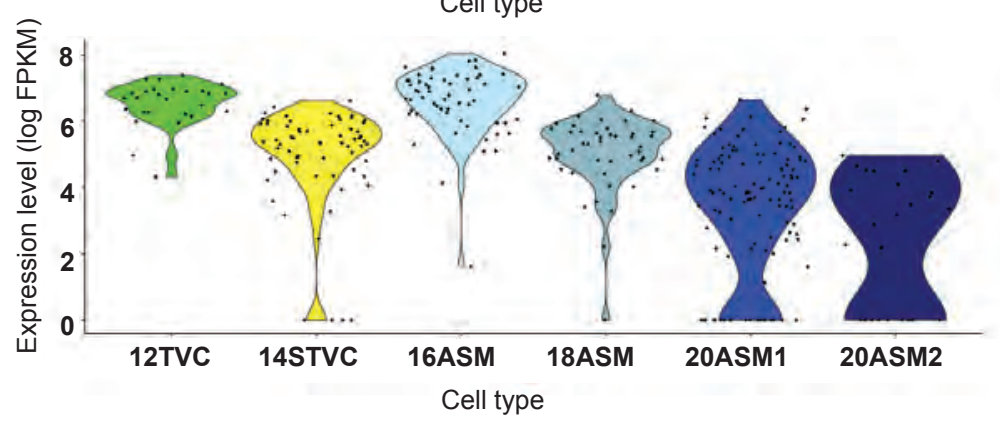

\section{Supplemental fig. 4}

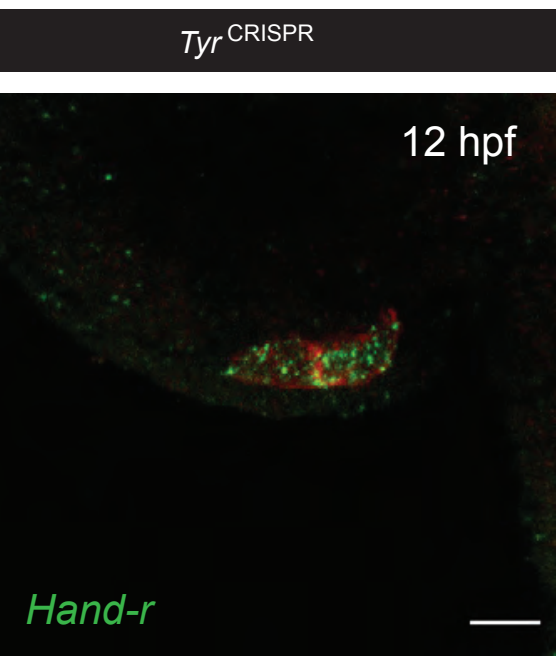

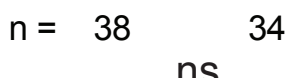

ns

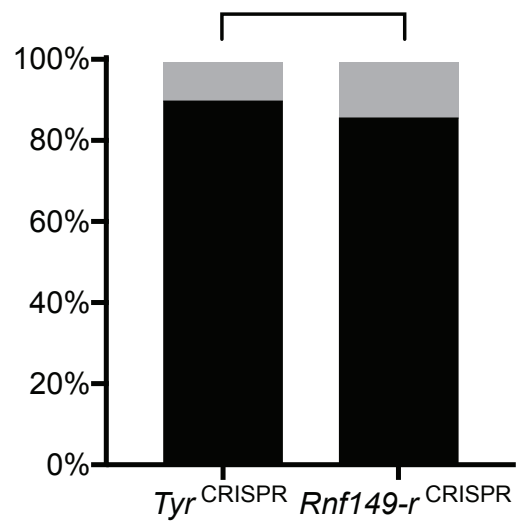

Hand-r 12 hpf

Downregulation

WT pattern 


\section{Supplemental fig. 5}

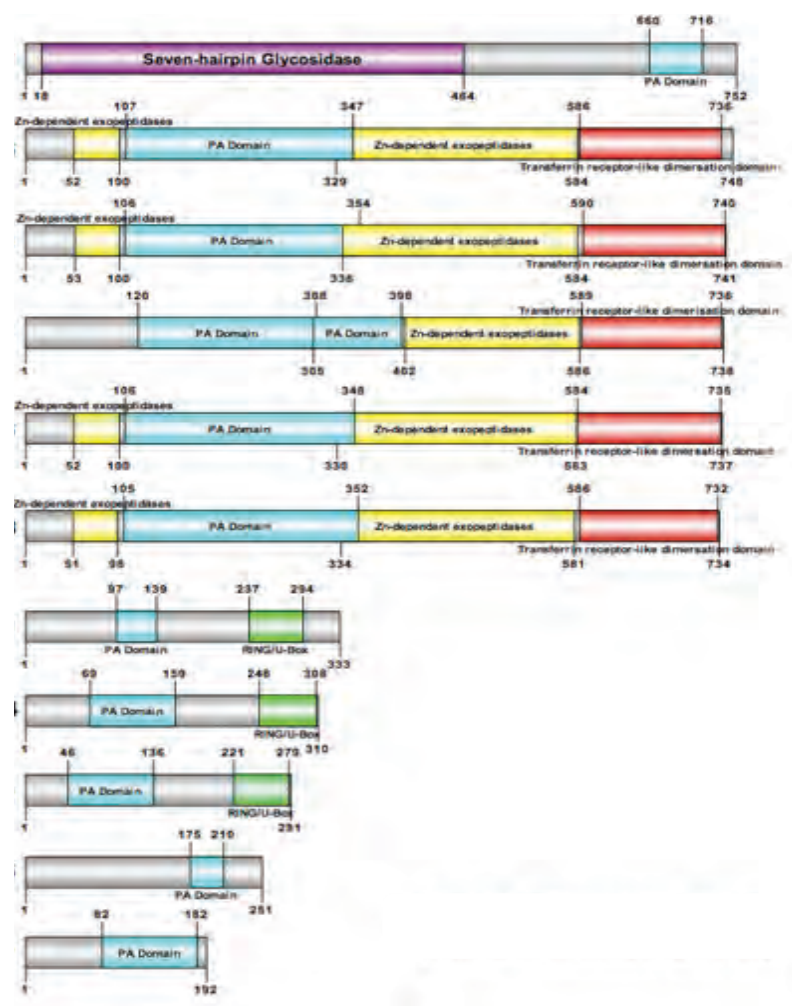

\section{Supplemental fig. 6}

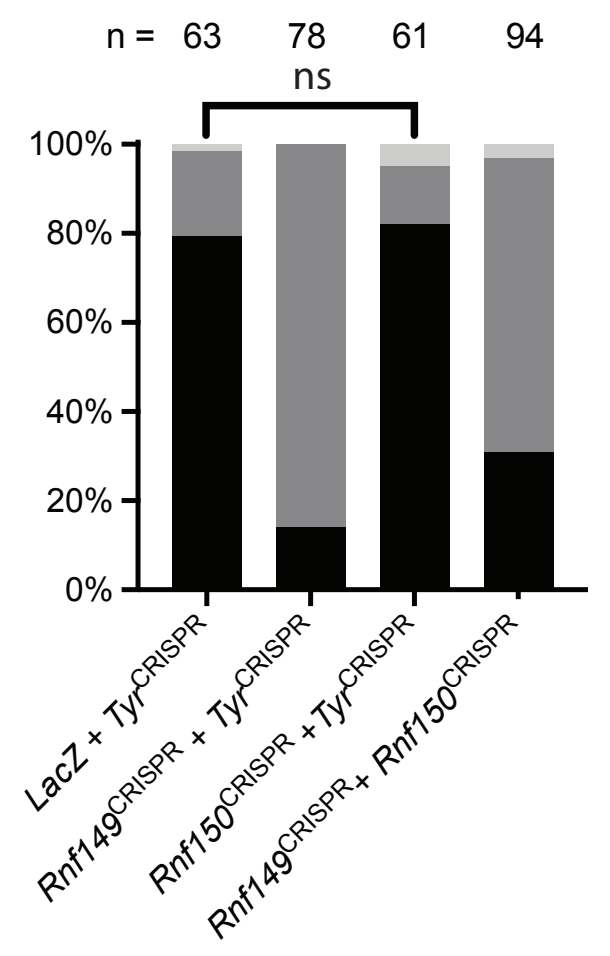

Supplemental fig. 7

$$
n=29 \quad 29 \quad 39 \quad 30 \quad 45 \quad 60
$$

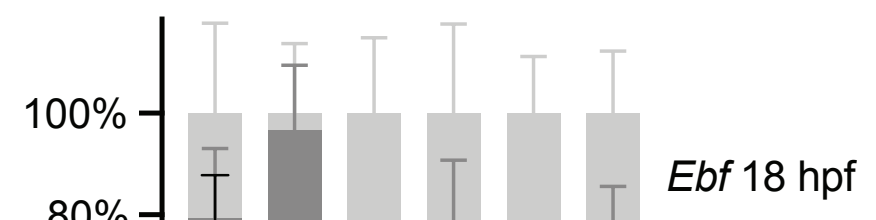

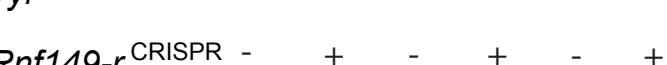

\section{Foxf $>$ LacZ}

Foxf $>$ MRas ${ }^{\mathrm{CA}}$

Foxf $>M e k^{\mathrm{CA}}$ 